\title{
BIOLOGIA E ASPECTOS MORFOLÓGICOS DE Brachymeria (Brachymeria) deata (SAY, 1824) (Hymenoptera: Chalcididae) ENDOPARASITO DE PUPAS DE LEPIDOPTERA
}

ORLANDO SHIGUEO OHASHI

Engenheiro Agrônomo

Orientador: Dr. EVONEO BERTI FILHO

Tese apresentada à Escola Superior de Agricultura "Luiz de Queiroz", da Universidade de São Paulo, para a obtenção do título de Doutor em Ciências, Área de Concentração: Entomologia.

PIRACICABA

Estado de São Paulo - Brasil Junho - 1984 
A minha esposa Orlandina

e aos meus filhos Roberta, Jūnior e Roberto, DEDICO .

A minha mae, ao meu pai (in memorian)

e aos meus irmãos, 


\section{AGRADECIMENTOS}

Externamos nossos sinceros agradecimentos a todas as pessoas e instituições que, direta e indiretamente cola boraram para a realização do curso de Pôs-Graduação em Entomologia e na execuçao deste trabalho, especialmente às relaciona das a seguir:

- A Faculdade de Ciências Agrárias do Pará, principalmente aos professores Miracy Garcia Rodrigues e Virgílio Ferreira Libonatti, pela oportunidade e confiança para a realização des te curso.

- Ao Dr. Evoneo Berti Filho, Professor Adjunto do Departamento de Entomologia da ESALC/USp, nela orientação e constante incentivo na execução áeste trabalho e pela versão do resumo para o inglês.

- Aos Professores Dr. José Roberto Postali Parra e Dr. Roberto Antonio Zucchi, pelas sugestões e estímulos.

- Aos Professores do Curso de Pós-Graduação em Entomologia da ESALQ/USP, pelos valiosos ensinamentos transmitidos. 
- A Drạ Marinéia de Lara Haddad, da Empresa Brasileira de Pesquisa Agropecuária, pelas anälises estatísticas.

- Ao Dr. Luis de Santis do ivuseu de la Plata na Argentina, pela identificação do parasito.

- Ao Engenheiro Florestal Martin Rodrigues Lopes Filho, pela $\underline{i}$ nestimável colaboração prestada na execução de alguns experí mentos.

- A CAPES pela concessão de uma bolsa de estudo.

- A Companhia Champion Papel e Celulose S/A nas pessoas dos Egenheiros Florestais Antonio Sérgio Diniz e Adalberto Plínio, pelas facilidades concedidas durante as coletas de mate rial, e pelo fornecimento dos dados climáticos.

- Aos alunos do Curso de Pós-Graduação em Entomologia da ESALQ, pela amizade.

- Aos funcionários do Depto de Entomologia, da Secretaria de Pós-Graduação e da Biblioteca da ESALQ, pela atenção e serví ços prestados. 


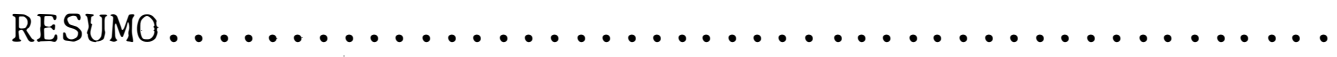

1. INTRODUCAO ........................ 1

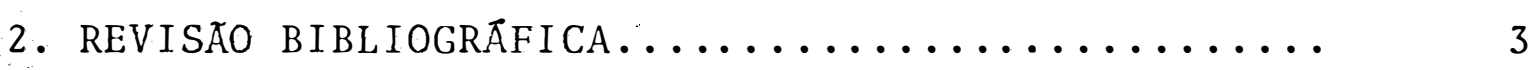

2.1. Sistemática e aspectos morfológicos........ 3

. 2.2. Distribuição geogräfica e hospedeiros....... 4

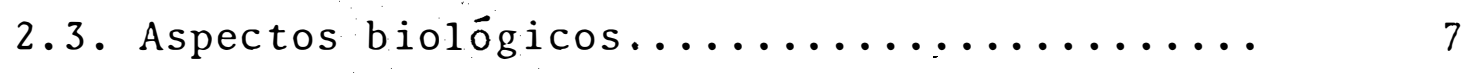

3. MATERIAL E METODOS..................... 9

3.1. Coleta de pupas e obtenção do parasito...... 9

3.2. Identificação da espécie............... 11

3.3. Hospedeiro para a multinlicação do parasito. $\quad 12$

3.4. Biologia e aspectos morfológicos........... 12

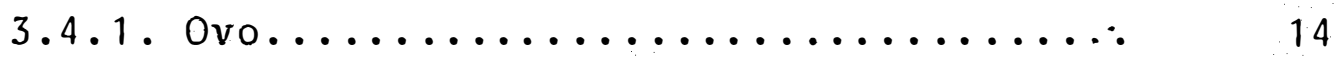

$3.4 .2 . \mathrm{Jarva} \ldots \ldots \ldots \ldots \ldots \ldots \ldots \ldots \ldots$

3.4.3. Pré-pupa e pupa............... 19

3.4 .4 . Adulto...................... 19

3.5. Ciclo de $B$. ovata em temperaturas constantes 21

3.6. Determinação da temperatura base $\left(\mathrm{T}_{\mathrm{b}}\right)$ e da constante térmica $(K)$ de B. ovata.......... 
3.7. Determinação do nümero de gerações de $B$. ova ta, com base no limiar de desenvolvimento e

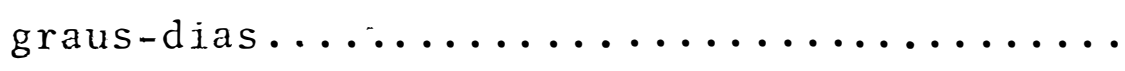

3.8. Interações parasito-hospedeiro.......... 24

3.8.1. Consumo de oxigênio $\left(\mathrm{O}_{2}\right) \ldots \ldots \ldots \ldots .24$

3.8.2. Redução do peso do hospedeiro...... 25

3.8.3. Desenvolvimento de B. ovata em hospedeiro morto................. 26

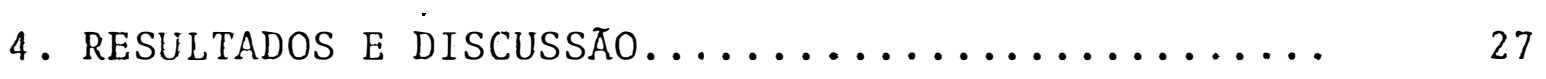

4.1. Hospedeiros.................... 27

4.2. Biologia e aspectos morfológicos.......... 28

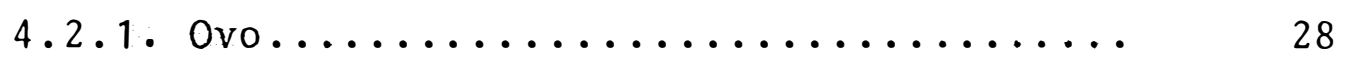

4.2.2. Larva.................. 28

4.2.3. pré-pupa................ 34

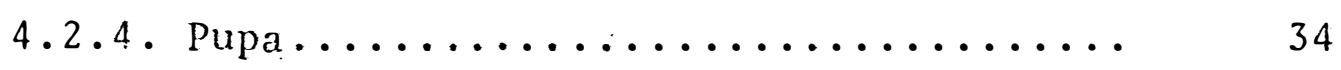

4.2.5. Adultos.................. 36

4.2.5.1. Aspectos gerais......... 36

4.2.5.2. Identificação da espécie... 43

4.2.5.3. Genitâlia completa do macho. $\quad 49$

4.3. Métodos para determinação dó número de ínsta

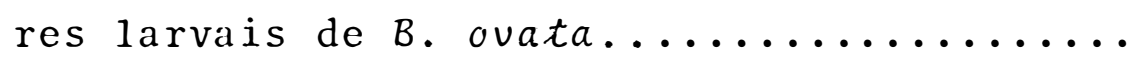


4.3.1. Curva de distribuição de freqüência do do diâmetro do espiráculo, do comprimento da barra transversal do tentório, da largura da máscara bucal e da largura da cāp

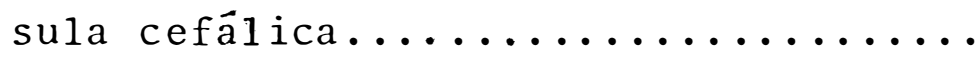

4.3.2. Crescimento progressivo do diâmetro do espiráculo, do comprimento da barra tento rial e da largura da máscara bucal......

4.3.3. Método obtido da própria regra de Dyar

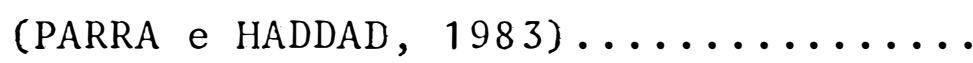

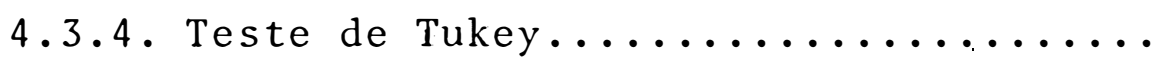

4.3.5. Comparação dos métodos para determinação do número de ínstares.......... 61

4.4. Ciclo em temperaturas constantes...........

4.5. Temperatura base $\left(\mathrm{T}_{\mathrm{b}}\right)$ e constante térmica (K)

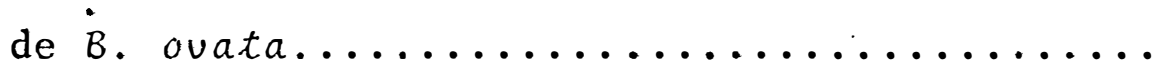

4.6. Determinação do número de gerações de B. •vata para Altinópolis e Moji-Guaçu em São Paulo,

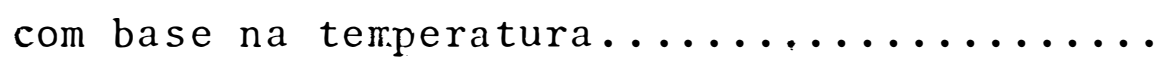

4.7. Interação parasito-hospedeiro.......... 70 4.7.1. Consumo de $0_{2} \ldots \ldots \ldots \ldots \ldots \ldots \ldots$ 
.viii.

Pāgina

4.7.2. Redução do peso do hospedeiro......

4.7.3. Desenvolvimento de B. ovata em hospe deiro morto em nitrogênio líquido $\left(\mathrm{N}_{2}\right)$

4.7.4. Avaliação da interação parasito-hos-

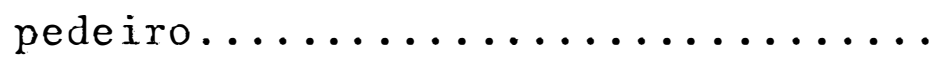

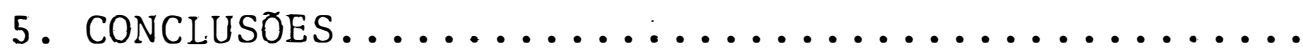




\section{BIOLOGIA E ASPECTOS MORFOLÓGICOS DE Brachymeria (Brachymeria) ovata (SAY, 1824) \\ (Hymenoptera：Chalcidid DAE) ENDOPARASito DE PUPAS DE LEPIDOPTERA}

AUTOR: ORLANDO SHIGUEO OHASHI

ORIENTADOR: DR, EVONEO BERTI FILHO

\section{RESUMO}

O objetivo deste trabalho foi estudar a biologia e a morfologia de Brachymeria (B.) ovata (Say, 1824) no laboratório de Entomologia da ESALQ/USP sob a tenperatura de $27 \pm 1^{\circ} \mathrm{C}$ e em câmaras climatizadas reguladas à $18,20,22,25,30$ e $32^{\circ} \mathrm{C}$. Foi utilizado como hospedeiro pupa de Spodoptera frugiperda (J.E. Smith, 1797). Observou-se diariamente parâmetros para determinação dos seguintes aspectos:

- ovo: período de incubação e viabilidade;

- larva: duração e dimensões da cápsula cefálica, máscara bucal, espiráculo e comprimento do corpo;

- pupa: duração, sexo e tamanho;

- adulto: período de pré-oviposição, número de ovos e de proge nie por fêmea, proporção sexual e longevidade;

- ciclo: duração do ovo à emergência do adulto; 
- interação parasito-hospedeiro: redução do peso e alteração da respiração em pupas parasitadas e desenvolvimento do para sito em pupas mortas.

Estudaram - se os caracteres morfológicos do ovo, larva e adulto (inclusive genitália do macho). Determinou-se o numero de instares larvais pelos métodos: curva de distribuição de freqüência, crescimento do diâmetro do espiráculo, método obti do da própria regra de Dyar e tește de Tukey. Através dos ciclos obtidos nas temperaturas constantes, determinou-se a temperatura base e a constante térmica, pelo método da hipérbole. A partir destes, estimou-se o número de gerações de B. ovata em Altinópolis e Moji-Guaçu (SP). Os principais resultados obtidos para B. ovata, foram:

- constante térmica de 198 graus-dias e temperatura base de 14,1300;

- faixa ótima de desenvolvimento de 25 à $300 \mathrm{C}$;

- a área de Altinópolis (SP) é mais favorável do que a de Moji-Guaçu (SP) ;

$\therefore$ é um parasito saprófita facultativo;

- as larvás apresentam 5 ínstares pelo crescimento do espirácu 10 e seguem a regra de Dyar;

- uma fêmea põe em média 287,67 ovos durante 65 dias de 1 ongevidade e produz 240 adultos numa proporção de 2 fêmeas: 1 ma cho; 
- os espécimens brasileiros apresentam caracteres diferentes dos neārticos, que provavelmente caracterizam uma subespécie de B. ovata. 


\title{
BIOLOGY AND MORPHOLOGICAL ASPECTS OF \\ Brachymeria (Brachymeria) ovata (SAY, 1824) \\ (HYMENOPTERA, ChALCIDIDAE) \\ ENDOPARASITE OF LEPIDOPTERA PUPAE
}

\author{
AUTHOR: ORLANDO SHIGUEO OHASHI \\ ADVISER: DR. EVONEO BERTI FILHO
}

\section{SUMMARY}

This research deals with the biology and morphology of Brachymeria (Brachymerial ovata (Say) in laboratory conditions $(27 \pm 10 \mathrm{C})$ and in chambers held at constant temperatures of $180,20^{\circ}, 22^{\circ}, 25^{\circ}, 30^{\circ}$, and $32^{\circ} \mathrm{C}$. Pupae of Spodoptera frugiperda (J.E. Smith) (Lepidoptera, Noctuidae) were used as hosts. The following parameters were daily observed:

- egg: viability and incubation period;

- larva: larval period, dimension of head capsule, buccal mask, diameter of spiracles and body length;

- pupa: pupal period, sex and size;

- adult: preoviposition period, number of eggs and progenie per female, sex ratio and longevity;

- life cycle: from egg period to adult emergence; 
- parasite-host interaction: weight reduction and alteration of respiration of parasitized host pupae, and parasite development in dead host pupae.

The morphological characters of egg, larva and adult, including genitalia were studied as well. The number of instars was determined by the following methods: frequency distribution curve, spiracle diameter growth, Dyar's rule, and Tukey test. The termerature treshold and the thermal requirements, for the cycles ob tained at the constant temperatures, were determined by the hiperbole method. These data were used to estimate the number of generations of B. ovata in Altinópolis and Moji-Guaçu, State of São Paulo, Brazil. The results were as follows:

- thermal requirements of 198 day-degrees and temperature treshold of $14.13^{\circ} \mathrm{C}$;

the optinum temperature range is from $25^{\circ}$ to $30^{\circ} \mathrm{C}$;

- the region of Altinópolis is more favourable for B. ovata development than that of Moji-Guaçu;

- B. ovata is a facultative saprophagous parasite;

- B. ovata larvae present five instars according to the growth of spiracle diameter;

- the larval development follows Dyar's law;

- each B. -uata female oviposits a mean of 287.67 eggs during 65 days of longevity, and produces 240 adults with a sex ratio of 2 \&: $10^{\circ}$; 
- the Brazilian species presents characteres different from those of the Neartic ones, which probably characterize a subspecies of B. ovata. 


\section{IHTRODUUCÃO}

Brachymeria ovata (Say, 1824) è um calcidídeo en doparasito de pupas de um grande número de lepidópteros de imtância agrícola e florestal (NE SANTIS, 1980 e BERTI FlLHO, 1981).

No Estado do Novo México, nos EUA, foi cúservado em 1976, em parasitismo natural por $\bar{B}$. ovata de $82^{\circ}$ das pupas de Hemileuca oliviae Cockerel (Lep.-Saturniidae). Por isso foi - objeto de estudo por PATANA et alii (1978) e PATANA (1979) para verificar a possibilidade do uso desse parasito no controle da referida praga.

No Brasil, estudo realizado por OHASHI (1978) mostrou que B. ovata parasitou cerca de $80 \%$ das pupas de Eupseudo soma aberrans e $E$. involuta, em eucaliptais do município de T'u paciguara em Minas Gerais. Neste trabalho observou-se que esse parasitóide ataca outras pragas importantes do eucalipto como Thyrinteina arnobia (Stol1, 1872), Sarsina violacens (Herrich- 

e Glena sp.

Então devido a importância de B. ovata no contro le natural de algumas pragas florestais, e tambēm pela escassez de informações sobre esse parasito, propô-se neste traba1ho, através de estudos de laboratório, sobre pupas de spóaptera frugiperda (J.E. Smith, 1797), determinar o ciclo biológi co, número de ínstares larvais, produção de progênio por fêmea, exigências térmicas, número de gerações durante o período de ocorrência das pragas, e a interação parasito-hospedeiro, $\underline{v}$ sando fornecer subsídios para o controle biológico de pragas flo restais. Outro objetivo foi estudar caracteres morfológicos pa ra facilitar a identificação da espécie. 


\section{REVISÃO BIBLIOGRÁFICA}

Brachymeria ovata é um inseto pouco estudado, prin cipalmente no Brasil, onde os trabalhos apresentam apenas 1 is tagem dos hospedeiros.

Devido essa escassez de trabalhos, parte da lite ratura citada na metodologia e discussão desta pesquisa, foi baseada em espécies afins ou aspectos correlatos com o assunto estudado.

\subsection{SiSTEMÁTICA E ASPECTOS MORFOLÓEICOS}

O gênero Brachumeria Westwood, 1829, era incluído do em Chalcis e apresenta mais de 150 espécies (DOWDEN, 1935). BURKS (1936) estudou 5 espécies de Brachymeria no 
Estado de Illinois, nos Estados Unidos da América, e descreveu alguns caracteres morfológicos de B. ovata, inclusive apresentando figuras da cabeça, tórax e edeago. Posteriormente, o mes mo autor (1960) revisou esse gênero, estudando 27 espécies da América do Norte. Neste trabalho, foi feita uma chave para essas espécies, e B. ovata foi redescrita baseando - se na fê mea. Foram apresentadas, também, figuras das faces laterais a cabeça, pronoto e fêmur posterior, onde existem caracteres con siderados importantes para diferenciar $B$. ovata das demais espécies. O gênero Brachymeria foi subdividido em. 5 subgêneros e B. ovata foi classificada no subgênero Brachymeria. DE SANTIS (1980) tambér a classificou assim, quando identificou 16 espécies que ocorrem no Brasil.

\subsection{DISTRIBUICÃ̃O GEOGRÁFICA E HOSPEDEIROS}

A maioria das espécies do gênero Brachymeria é encontrada nos climas tropicais e subtropicais, entretanto algumas espécies são comuns na zona temperada (DOWDEN, 1935).

B. ovata tem como localidades tipos Ohio e Pennsylvania nos EUA. (BURKS, 1960), mas distribui-se pelas regiões Neártica e Neotropical como parasito primário de pupas de mais de 100 espécies, em 18 familias de Lepidoptera (BURKS, 1960 e DE SANTIS, 1969). Entretanto, PATANA (1979) citou que tambëm parasita pupas de Diptera. 
A seguir é citada uma relação de hospedeiros pertencentes a ordem Lepidoptera, que são parasitados por B. ovata e na seguinte sequência: espécie, família, autores e datas das publicações.

- Alabama argillacea (Huebner, 1818), Noctuidae: COSTA LIMA, 1962; SILVA et alii, 1968 (parasito secundärio do iquineumoníceo Ephialtis bazani) e DE SANTIS (1980).

- Ascia monuste orseis (Godart, 1818), Pieridae: COSTA LIMA, 1962 .

. A. monuste monuste (L., 1764), Pieridae: DE SANTIS, 1980.

- Brassolis astyra astyra (Godar, 1765), Brassolidae: SILVA e.t alii, 1968 e DE SANTIS, 1980.

- B. sophorae sophorae (L., 1758), Brassolidae: SIlVA et alii, 1968 e DE SANTIS, 1980.

- Choristoneura fumiferana (C1emens), Tortricidae: DROOZ e BEN JAMIN, 1956.

- Cincinnus despecta (Walker, 1855), Mimallonidae: COSTA LIMA, 1962 e DE SANTIS, 1980. 
- Epipagis cambogialis (Guenēe, 1854), Pyralidae: DE SANTIS, 1980 .

- Eupseudosoma aberrans Schaus, 1905 e E. involuta (Sepp, 1852), Arctiidae: OHASHI, 1978.

- Eupseudosoma spp., Arctiidae: BERTI FILHO, 1981.

- Euselasia sp., Erycinidae: DE SANTIS, 1969.

- Euselasia apisaon (Da1man, 1823), Erycinidae: GALLOet alii, 1978

- Euselasia euploea eucerus (Hewitson, 1872), Erycinidae: MACE DO, 1975 e BERTI FILHO, 1981 .

- Hedylepta indicata (Fabricius, 1775), Pyralidae: BOFTOLI et alii, 1982 .

- Hemerocampa vetusta (Boisduva1), Lymantriidae: ATKINS Jr., 1958

- Hemileuca oliviae (Cockere1), Saturniidae: PATANA, 1979.

- Lymire edwardsie (Grote), Ctenuchidae: GENUNG, 1959. 
- Mocis spp., Noctuidae: OGUNWOLU e HABECK, 1975.

- Mocis latipes (Guenée, 1852), Noctuidae: LOURENCTO et alii, 1982 (parasito secundārio em pupas de Tachinidae).

- Papilio thoas brasiliensis Rothschild e Jordan, 1906, Papilio nidae: SILVA et alii, 1968 e DE SANTIS, 1980.

- Sarsina violascens (Herrich-Schaeffer, 1856), Lymantriidae: SILVA et alii, 1.968; DE SANTIS, 1980 e BERTI FILHO, 1981.

\subsection{ASPECTOS BIOLÓGICOS}

PATANA et alii (1978) estudaram o desenvolvimento do ovo até a emergência do adulto de $B$. ovata em 6 hospedei ros sob 5 temperaturas constantes. Em Pectinophora gossypiella, esse ciclo variou de $10,4 \pm 0,7$ dias a $57,1 \pm 2,1$ dias, respec tivamente à $35^{\circ} \mathrm{C}$ e $15^{\circ} \mathrm{C}$. Em Spodoptera exigua e Trichoplusia $n i$, variou de $11,5 \pm 0,6$ dias a $28,9 \pm 1,6$ dias, respectivamente à $35^{\circ} \mathrm{C}$ e $20^{\circ} \mathrm{C}$. O ciclo foi similar em Heliothis virescens, $H$. zea e Estigmene acrea, variando de $12,2 \pm 0,8$ dias a $34,6 \pm 7,4$ dias, respectivamente à $35^{\circ} \mathrm{C}$ e $20^{\circ} \mathrm{C}$. Os autores ainda consideraram a temperatura de $15^{\circ} \mathrm{C}$ como próxima da temperatura base, porque pou cos exemplares desenvolveram-se nessa temperatura e a faixa de $25^{\circ} \mathrm{C}$ a $30^{\circ} \mathrm{C}$ como a ótima para o desenvolvimento, embora a últi 
ma pareça ser a melhor para a produção do parasito em laboratō rio.

Tambẻm a fase adulta foi estudada sob 4 temperaturas constantes por PATAiva (1979). Os períodos de pré-ovipos $\underline{i}$ ção, oviposição e longevidade aumentaram quando a temperatura variou de $35^{\circ} \mathrm{C}$ para $20^{\circ} \mathrm{C}$. A temperatura de $30^{\circ} \mathrm{C}$ mostrou-se como a mais adequada, porque nela foi obtida a maior progênie por fêmea e tambêm um maior número de fêmeas por progênie. Ainda, os machos desenvolvidos à $35^{\circ} \mathrm{C}$ foram geralmente estēreis e as fêmeas não copuladas produziram apenas machos em todas as temperaturas estudadas.

THOMPSON (1981), usando dietas quimicamente defi nidas, demonstrou que a larva de B. ovata necessita de 10 amznoácidos essenciais. 


\section{MATERIAL E PIÉTODOS}

Este trabalho foi desenvolvido nos laboratórios do Departamento de Entomologia da Escola Superior de Agricultu ra "Luiz de Queiroz", da Universidade de São Paulo, em Piracicaba.

\subsection{COLLETA DE PUPAS E OBTENCÃO DO PARASITO}

Foram feitas diversas coletas de pupas de Eupse $\underline{u}$ dosoma aberrans, E. involuta (Lep.-Arctiidae), oxidia sp., Gle na sp., Thyrinteina arnobia (Lep.-Geometridae) e Psorocampa denticulata (Lep.-Notodontidae) em eucaliptais de Tupacigura (MG), Altinópolis, Moji-Guaçu e Itupeva (SP). As pupas foram mantidas no laboratório em pequenas gaiolas de vidro com uma das fa ces telada, apoiada sobre placa de Petri (Figura 1) até a emer 


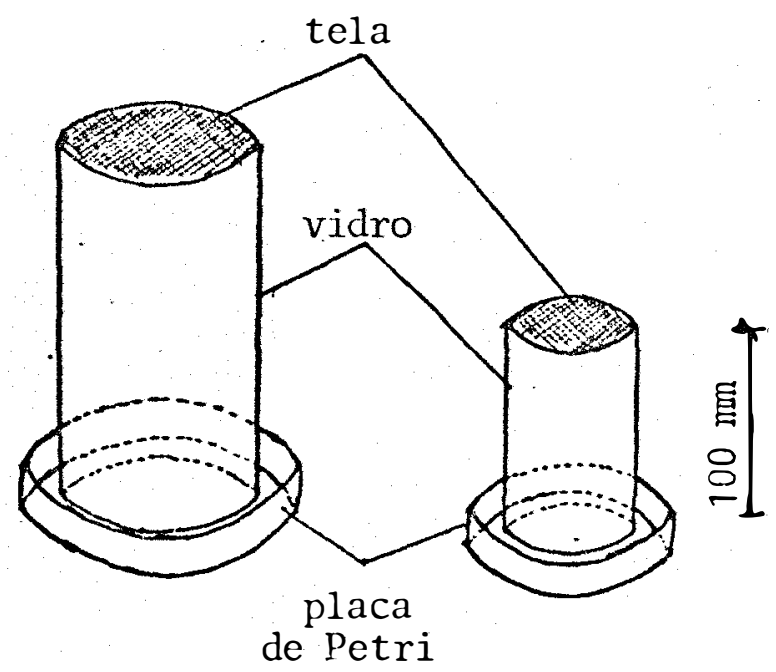

Figura 1 - Gaiolas de vidro com um das faces telada, apoiada sobre placas de Petri, usadas para emergência e criação de $B$. ovata (OHASHI, 1978).

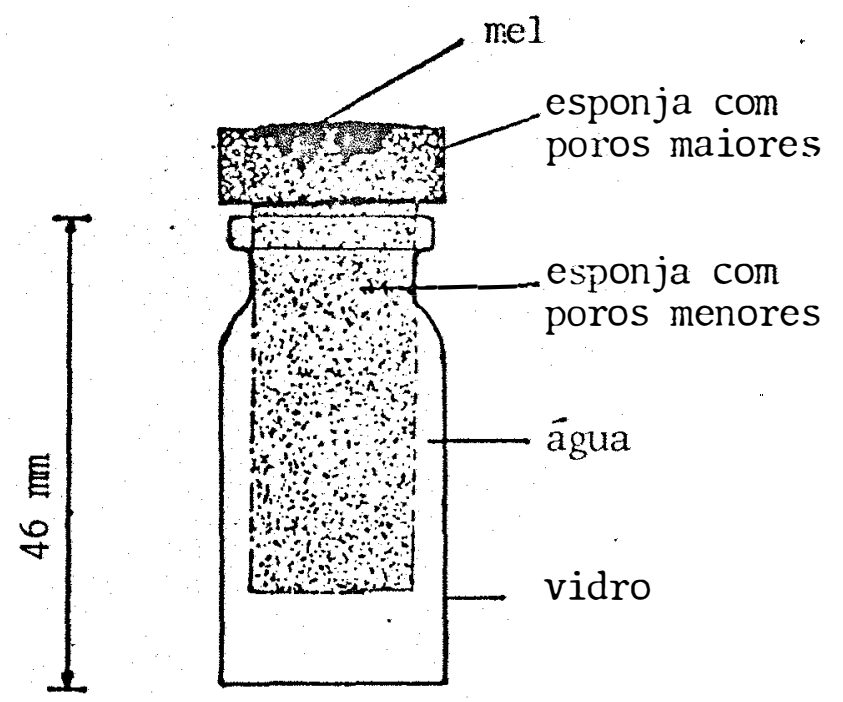

Figura 2 - Frasco de vidro com esponja plástica, utilizado para servir água e mel aos adultos de B. ovata (OHASHI, 1978). 
gência dos parasitos e/ou das pragas. Emergiram diversas espécies de parasitos, entretanto só foram mantidos e alimentados, com água e mel oferecido de acordo com a Figura 2, aqueles pertencentes ao gênero Brachymeria.

\subsection{IDENTIFICACÃO DA ESPÉCIE}

Após a devida montagem e etiquetagem de alguns espécimens machos e fêmeas em alfinete e/ou álcool 70\%, esses insetos foram remetidos ao Dr. Luis de Santis, do Museu de la Plata na República Argentina, que identificou a espēcie como Brachymeria ovata (Say, 1824). Após esta identificação os adul tos desse parasito, coletados no campo e criados no laboratório, foram identificados por comparação à cópia do material en viado ao especialista e também com o auxílio da bibliografia. 


\title{
3.3. HOSPEDEIRO PARA A MULTIPLicAcão do PARASito
}

\begin{abstract}
Durante as coletas relatadas no item $3.1 .$, tambēm foram coletadas lagartas para obtenção de pupas para a reprodução do parasito, entretanto, houve uma grande mortalidade das lagartas por parasitos e doenças que tornou impraticável a criação desses lepidópteros. Por isso, durante este trabalho foi utilizado, como hospedeiro alternativo, pupas de spodoptera frugiperda (J.E. Smith, 1797) (Lep.-Noctuidae) com un dia de idade e cuja criação foi mañtida continuamente em laboratório sobre dieta de feijão de acordo com a composição e preparação citadas por PARRA (1979).
\end{abstract}

\section{4: BIOLOGIA E ASFECTOS MORFOLÓGICOS}

Esse experimento foi executado numa sala com tem peratura de $27 \pm 1^{\circ} \mathrm{C}$ e umidade relativa de $78 \pm 8 \%$, medidos e registrados por um termo-higrógrafò. 
Neste experimento utilizaram-se pủpas de $S$. frugiperda com pesos mais ou menos padronizados, pois de acordo com ASKEW (1971) e PATANA et alii (1978), o tamanho do hospedeiro pode influenciar o tamanho do parasito. Ainda segundo ROJAS-ROUSSE e BENOIT (1977), reduz-se a variação de diferentes medidas do para sito, usando-se hospedeiros de mesma idade, pesos idênticos e contendo apenas um ovo do parasitóide. Portanto optou-se por $\underline{u}$ tilizar pupas com peso de $261 \mathrm{mg}$ a $297 \mathrm{mg}$, classe de maior fre qüência ( $50 \%$ ) dentre 5 grupos de uma amostra de 50 individuos, a fim de se tentar minimizar a influência desse fator ro caranho do parasitóide.

Cada hosfedeiro dessa classe foi parasitacia ura única vez, por um dos vinte casais de B. ovata manticios rara esse fin. Em seguida o hospedeiro foi colocado em tuio de vidro $(8,5 \mathrm{~cm}$ de comprimento $x 2,5 \mathrm{~cm}$ de diâmetro) vedado com al godão, onde se anotava o dia e a hora do parasitismo, a fïm de que, a cada dia após a postura fosse dissecacia a pupa e observada a fase do parasitóide. Essa dissecação foi feita até o 13 ? dia, observando-se 40 pupas parasitadas por dia. 
O ciclo total do parasito (ovo até emergência do adulto) foi observado paralelamente ao das fases jovens, aproveitando-se as pupas parasitadas para se medir o número de ovos por fêmea de B. ovata (item 3.4.4.).

\subsubsection{0vo}

Para determinar o período de incubação foi feita mais uma dissecação de pupas com 30 horas de parasitismo. A fim de melhor se estimar a duração e a viabilidade dessa fase, observou-se o desenvolvimento de 100 ovos submersos em solução fisiológica. Esses ovos foram retirados cuidadosamente de pupas recém-parasitadas e mantidos na solução em pequenos frascos de vidro à temperatura ambiente e no escuro, onde foram ob servados a cada meia hora, àepois das primeiras 24 horas, até a eclosão da larva. Foram medidos o comprimento e a largura de 50 ovos recém-postos. Foi desenhado o ovo, usando-se uma cämara clara acoplada a um microscöpio estereoscópico Wild M7A. 


\section{$3,4,2$, LARVA}

Esta fase foi estudada sobre insetos mortos em mistura de KAAD (VANZOLINI e PAPAVERO, 1967). Foram observados e/ou medidos os seguintes parâmetros:

a) forma e cor da larva;

b) número de segmentos do corpo;

c) número de espiráculos abertos;

d) largura da cápsula cefálica ou largura máxima cia cabeça;

e) comprimento do corpo;

f) largura da máscara bucal - distância entre as paredes inter nas do pleurostoma;

g) comprimento da barra transversal do tentório que corresponde a distância intermetatentorial citado por ROJAS-ROUSSE e BENOIT (1977);

h) diâmetro do espiráculo nesotorácico - largura do orifício mais a espessura do peritrema.

Com o uso de uma câmara clara, acoplada ao microscópio, foram feitas figuras da cabeça e do corpo para methor caracterizar esses parâmetros, cuja nomenclatura foi baseada nos trabalhos de VANCE e SMITH (1933), DOWDEN (1935) e ROJAS-ROUSSE E BENOIT (1977).

Os três ültimos parâmetros foram observados em larvas diafanizadas e montadas em lâminas escavadas com bảlsa- 
mo do Canadá, sem usar laminula para evitar a deformação das. estruturas, bem como facilitar a colocação de cada parâmetro na posição exata de cada medida microscópica.

A diafanização consistiu em passar o inseto na seguinte seqüência de produtos químicos, à temperatura ambiente: $24 \mathrm{~h}$, em KOH à $10 \%, 24 \mathrm{~h}$ em creosoto, $30 \mathrm{~min}$ em corante car mim acético (LANDIN e BEIG, 1966) e novamente por $15 \mathrm{~min}$ em creo soto. Geralmente as larvas com mais de dois dias de idade, forari perfuradas ventralmente com estilete para facilitar a saía do te cido gorduroso.

A determinação do nümero de ínstares foi baseada nos seguintes trabalhos:

ROJAS-ROUSSE e BENOIT (1977) - o diâmetro do es piráculo, largura da máscara bucal e distância intermetatentorial, mas principalmente o primeiro foi o parâmetro mais seguro para distinguir os instares em Hymenoptera parasiticos porque são estruturas esclerosadas que crescem progressivamente a cada instar:

PARRA e HADDAD (1983) - o número de instares é considerado de fundamental importância na biologia dos insetos e pode ser determinado por métodos indiretos aplicados principalmente, para o crescimento progressivo da cápsula cefálica ou regra de Dyar, seguida geralmente pelas lagartas, mas que já foi validada para outras ordens, inclusive Hymenoptera.

Assim foram usados os seguintes métodos: 
A - Curva de distribuição de freqüencia - as medidas dos parâmetros: larguras da cápsula cefálica è da máscara bucal, comprimento da barra transversal do tentōrio e diâmetro do espiráculo, foram inicialsente agrupadas pela freqüência observada e depois plotados em histogramas de barras, onde se observou o número de instares pelos picos mais evidentes;

B - Crescimento ou "saltos" do diâmetro do espiräculo - neste método o nümero de ínstares foi indicado pelos "saltos" des te parâmetro, principalmente das larvas mortas durante o processo de ecdise, onde foram visiveis a existência de 2 espiráculos sucessivos e nitidamente diferentes pelo diâme tro.

As medidas da máscara bucal e barra transversal do tentório, bem como os histogramas desses parâmetros, au xiliaram no estabelecimento dos 1 imites de cada instar.

C - Método obtido da prōpria regra de Dyar por PARRA e HADDAD en 1983 - aplicado aos valores da cápsula cefálica e másca ra bucal, e consiste no emprego das seguintes equações:

$$
\mathrm{CC}_{\mathrm{i}}=\mathrm{K} \cdot \mathrm{CC}_{\mathrm{i}-1}+\mathrm{e}_{\mathrm{i}} \text {; onde: }
$$

$\mathrm{i}($ instar $)=2,3, \ldots, \mathrm{m}$; 
$\mathrm{CC}_{\mathrm{i}}=$ valor médio da cápsula ceśálica no grupo i;

$\mathrm{CC}_{\mathrm{i}-1}$ = valor médio da cápsula cefálica no grupo anterior a i;

$e_{i}=\operatorname{erro}, e_{1} \cap N\left(0, \sigma^{2}\right)$;

$\mathrm{m}=$ nümero total de instares.

$$
\hat{K}=\frac{\sum_{i=2}^{m} \cdot C C_{i-1} \cdot C C_{i}}{\sum_{i=2}^{m}\left(C C_{i-1}\right)^{2}} \text {, onde: }
$$

$\hat{K}=$ valor estimado da constante $K$.

$$
\hat{R}^{2}=1-\frac{\sum_{i=2}^{m}\left(C C_{i}-C \hat{C}_{i}\right)^{2}}{\sum_{i=2}^{m}\left(C C_{i}-\overline{C C_{i}}\right)^{2}} \text { onde : }
$$

$\mathrm{R}^{2}=$ coeficiente de determinação;

$C \hat{C}_{i}=$ valor estimado pela regressão;

$\overline{\mathrm{CC}_{\mathrm{i}}}=$ valor médio de $\mathrm{CC}_{\mathrm{i}}$.

Os cálculos foram realizados por um Computador Prologica CP500 do Deptẹ de Entomologia, testando-se as hipóte ses de 5 e 6 instares nos dois parâmetros estudados.

D - Teste de Tukey - aplicado aos dados do diâmetro cos espirāculos que foram transformados em micra para a realizacão da anālise da variância e comparação das médias pelo refe- 
rido teste com nưnero de repetições diferentes, atravēs do computador COMNODORE-CBM-mode1o 302, do Centro de Energia Nuclear na Agricultura (CENA), em Piracicaba, SP. Foram também testadas as hipōteses de 5 e 6 instares.

\subsubsection{PRÉ-PUPA E PUPA}

Observou-se a duração e o desenvolvimento da pigmentação do corpo nas duas fases.

Na fase de pupa foi feita ainda a distinção dos sexos pelas dimensões de cápsula cefálica e do comprimento do corpo, cujos dados foram transformados, respectivamente, em $\sqrt{x+0,9}$ e $\sqrt{x+0,6}$ para a anālise da variância e comparação das médias pelo teste de Tukey ao nivel de $5 \%$ de probabili dade. Os cálculos foram realizados pelo computador CP500 do De partamento de Entomologia.

\subsubsection{ADULTO}

Foram observados em nove casais alimentados com mel e água, os seguintes parâmetros:

- cópula;

- período de pré-oviposição; 
- número total de ovos/fëmea;

- proporção sexual;

- produção de progênie/fêmea;

- longevidade.

Essas observações, exceto a cópula, tambēm foram realizadas em 4 fêmeas virgens.

Para determinar o número total de ovos/fêmea e a produção de progênie/fêmea, foram oferecidas, diariamente, à cada fêmea diversas pupas de $S$. frugiperda. Cada una após ser parasitada uma ūnica vez, foi depositado num frasco de vidro vedado com tampa plástica porosa, atē a emergência do parasitóide.

Foram medidos a cápsula cefálica e o comprimento do corpo de 30 machos e 30 fêmeas para verificar o dimorfis mo sexual. Os dados foram analisados pelo mesmo método do item 3.4 .3 .

Com o auxílio de câmaras claras foram feitás $f \underline{i}$ guras da fêmea em vistas lateral e dorsal, da antena, das mandíbulas, das asas, da perna posterior (parte), do abdome, em vista ventral e genitália do macho. As partes que necessitaram ser clarificadas, foram imersas durante 3 dias em $\mathrm{KOH}$ a $10 \%$ e 2 dias em creosoto a frio.

A nomenclatura empregada: às estruturas da genitālia do macho foi baseada no trabalho de VIGGIANI (1971) e, para as demais partes do corpo, nos trabalhos de BURKS (1960) e COSTA LIMA (1962). 


\subsection{CiClO DE B. ovata EM TEMPERATURAS CONSTANTES}

Essa pesquisa foi realizada em câmaras climatizadas BOD modelo 347 GANEM, reguladas para 14 de fotofase, onde se observou o ciclo do parasito (ovo até a emergência do adulto) em seis temperaturas constantes: $18,20,22,25,30$ e $32^{\circ} \mathrm{C}$.

Para cada temperatura foram colocadas 60 pupas parasita das, uma em cada tubo de dieta, tampado com algodão, estudando-se através de observações diārias, os seguintes parâmetros: duração do ciclo, sexo e : de emergência do parasitóide. 0 número de descendentes/fêmea/geração foi calculado pela seguinte förmula: $\frac{q}{q+\sigma^{\circ}} \times$ sobrevivência total $x \frac{\text { no ovos }}{\text { fêmea }}$.

\subsection{Determinaç̃o DA temperatura Base $\left(T_{b}\right)$ E DA CONStante TÉRMICA (K) DE B. ovata}

Com os dados da duração média do ciclo nas seis temperaturas citadas no item anterior, estimou-se a temperatura base ou limiar de desenvolvimento pelo método da hipérbole que, segundo HADDAD e PARRA (1984), consiste em linearizar a curva obtida em laboratório, através da recíproca de desenvolvimento, obtida da equação da constante térmica de Rèamur:

$$
K=D\left(T-T_{b}\right) \text {, onde: }
$$

$K=$ constante térmica em graus dias (GD);

$D$ = tempo de desenvolvimento (ảias); 
$\mathrm{T}=$ temperaturana qual o inseto se desenvolveu (OC);

$\mathrm{T}_{\mathrm{b}}=$ temperatura base $\left({ }^{\circ} \mathrm{C}\right)$.

A recíproca desta equaçao é a seguinte:

$$
\begin{aligned}
& \frac{1}{D}=-\frac{T_{b}}{K}+\frac{1}{K} T, \text { fazendo-se } \\
& Y=\frac{1}{D} ; \quad a=-\frac{T_{b}}{K} ; \quad b=\frac{1}{K} e \quad X=T \text {, obtëm-se } a
\end{aligned}
$$

equaçao de regressão linear $Y=a^{*} \dot{r} b x$, também chamada equação da velocidade de desenvolvimento ou de taxa de desenvolvinento. Por definição, o inseto paraliza seu desenvolvimento quando $Y=0$ (zero) e assim resultam as estimativas:

$$
\mathrm{T}_{\mathrm{b}}=-\frac{\mathrm{a}}{\mathrm{b}}{ }^{\circ} \mathrm{C} \quad \text { e } \quad \mathrm{K}=\frac{1}{\mathrm{~b}} \mathrm{GD} .
$$

Os valores de $T_{b}, K, R^{2}$ e os parâmetros $\underline{a} e \underline{b}$ da regressão $y=a+b x$, foram calculados pelo computa dor CP500 do Deptọ de Entomologia da ESALQ/USP. A partir dessa equação se estimou a velocidade e a duração de desenvolvimento nas seis temperaturas estudadas.

Para verificar a eficiência deste método, aplicou-se o teste de $x^{2}$, entre os valores do desenvolvimento observados e os estimados pela equação linear, bem como, se esta beleceu a relação gräfica entre o tempo de desenvolvimento observado e a velocidade de desenvolvimento em função da tempera 
tura.

Esses parâmetros também foram calculados para B. ovata desenvolvida em outros hospedeiros de acordo com os dados de PATANA et alii (1978).

3.7. Determinaç̃o do número de gerações DE B. ovata, COM BA SE NO LIMIAR DE DESENVOLVIMENTO EM RELACÃO À TEMPERATU RA MÉDIA MENSAL DO AR

Foram determinados para Altinōpol is e Moji-Guaçu no Estado de São Paulo, porque foram os únicos municípios, daqueles citados no item 3.1., que apresentaram dados climatológicos obtidos nos arquivos da Companhia Champion Papel e CeIulose S/A.

Considerou-se o período de abril a agosto, porque geralmente nesse período, ocorrem os lepidópteros Eupseudo soma aberrains, E. involuta e Thyrinteina arnobia, consideradas as principais pragas de Eucalyptus spp. em São Paulo. As duas primeiras ocorrem nos meses de abril e maio e a última espécie de junho a agosto (MACEDO, 1975; OHASHI, 1978 e BERTI FILHO, 1981).

Os cálculos foram realizados da seguinte forma (PARRA, 1981): 


$$
\begin{aligned}
n\left(t^{\circ} \mathrm{C}-t_{b}{ }^{\circ} \mathrm{C}\right)=K \rightarrow n=\frac{K}{t^{\circ} \mathrm{C}-t_{b}{ }^{\circ} \mathrm{C}} & \text { onde: } \\
n & =n \text { o de dias para completar o ciclo; } \\
t^{\circ} \mathrm{C}= & \text { temperatura média mensal; } \\
t_{b}{ }^{\circ} \mathrm{C}= & \text { temperatura base para todas as fases do ciclo; } \\
K & =\text { constante térmica para o desenvolvimento do ciclo. }
\end{aligned}
$$

Após os cālculos de $\mathrm{n}(\mathrm{s})$, o número de gerações mensais foi obtido dividindo-se 30 por $n$.

\subsection{INTERAÇÕES PARASITO-HOSPEDEIRO}

\subsubsection{CONSUMO DE OXIGÊNIO $\left(\mathrm{O}_{2}\right)$}

A metodologia foi baseada no trabalho de THOMPSON (1980), que observou o efeito do parasitismo de B. interme dia em pupas de Trichoplusia ni.

A respiração individual de 10 pupas parasitadas e 10 não parasitadas, mantidas numa câmara climática à $300 \mathrm{C}$ e $14 \mathrm{~h}$ de fotofase, foi medida diariamente através de um respirô metro de Warburg do Depto de Entomologia da ESALQ/USP, cuja tem peratura foi mantida constante à $26,5^{\circ} \mathrm{C}$ (máxima atingida pelo respirômetro) durante as observações. Antes de cada observação as pupas ficaram em adaptação ao ambiente do frasco de Warburg 
por 15 minutos. Mediu-se o consumo de $\mathrm{O}_{2}$ durante o período de 30 min, fazendo-se uma leitura a cada $10 \mathrm{~min}$. Esses dados foram transformados em taxa ou quociente respiratório $\left(\mathrm{mm}^{3}\right.$ de $\mathrm{O}_{2} /$ $\mathrm{mg}$ de peso vivo/min), de acordo com o trabalho de UMBREIT et alii (1964), sem considerar nesses cálculos a fase líquida ou fluida.

Os dados da taxa respiratória foram transformados em $\sqrt{x+0,8}$ para anālise de acordo com o delineamento ex perimental "Split-plot" inteiramente casualizado, onde a fonte de variação na parcela foi dia e na subparcela foi parasitismo (parasitado e não parasitado). Os cáiculos foram realizados pe 10 computador COMMODORE-CBM - mode1o 302 do CENA.

Paralelamente a esse experimento, observou-se o desenvolvimento do parasito, através de dissecação diária de 3 pupas parasitadas.

\subsubsection{REDUÇÃO LO PESO DO HOSPEDEIRO}

Neste ensaio foram utilizados 60 hospedeiros, sendo a metade parasitada. Esses insetos foram mantidos à $30^{\circ} \mathrm{C}$ e $14 \mathrm{~h}$ de fotofase.

Diariamente pesou-se cada inseto em uma balança digital METTLER AC 100 , ate ao 60 dia após o parasitismo, quan do as larvas passam a pré-pupa e pupa. Este desenvolvimentofoi observado em outro lote de 25 pupas parasitadas, dos quais e- 
ram dissecados 3 por dia.

Os dados de porcentagem de redução do peso, foram transformados em arc sen $\sqrt{\frac{x}{100}}$ e analisados pelo mesmo método citado no item 3.8.1.

\subsubsection{DESENVOLVIMENTO DE B. ovata EM HOSPEDEIRO MORTO}

Um lote de 50 hospedeiros foi morto por choque térmico mediante rāpidas imersōes em nitrogênio líquido do setor de Química do CENA. De acorào com WEAST (1976-1977), o nitrogênio no ponto de ebulição, atinge a temperatura de $-195,80^{\circ} \mathrm{C}$. Após ao equilíbrio térmico dos hospedeiros com o reio ambiente, 35 foram parasitados. Em seguida todo o lote, foi mantido à $300 \mathrm{C}$ e 14 horas de fotofase, para observar a emergência de parasitos. 


\section{RESULTADOS E DISCUSSÃO}

\subsection{HOSPEDEIROS}

Das 6 espécies de lepidópteros citados no item 3.1., somente Psorocampa denticulata não foi parasitada por $B$. ovata, apesar de ter sido coletado um grande número de pupas, desse lepidóptero no mesno plantio de eucalipto em Altinópolis (SP), onde as 5 outras espécies apresentaram-se parasitadas por $B$. ovata. E um parasito polífago, concordando com BURKS (1960).

$$
\text { Apesar de BORTOLI et alii (1982) terem afirmado }
$$

que B. ovata ataca Hedylepta indicata desde a fase de lagarta, esse parasitóide só atacou os hospedeiros referidos anteriormente, e também $S$. frugiperda, na fase de pupa. 


\subsection{BIOLOGIA E ASPECTOS MORFOLÓGICOS}

\subsection{1. ovo}

A viabilidade foi de $99 \%$ e o período de incubação de 26,3 h (I.V. $=24-29,5 \mathrm{~h})$ em solução fisiológica. Este resultado ficou dentro do período obtido pela dissecação de pu pas (Tabela 1), demonstrando assim que o desenvolvimento embrionārio ocorre normalmente em solução fisiológica e que, prọ vavelmente, a viabilidade seja de $100 \%$ dentro do hospedeiro. 0 ovo é himenopteriforme, ligeiramente curvado com as extremidades arredondadas (Figura 3), e muito semelhante ao da espécie B. intermedia, apresentado por DOWDEN (1935). O córion é liso e hialino, permitindo perceber, em solução fisiológica, que a larva eclode cortando o córion com as mandíbulas.

Mede $0,91 \mathrm{~mm}\left(I . V_{. .}=0,83-0,97 \mathrm{~mm}\right)$ de comprimento por $0,23 \mathrm{~mm}(\mathrm{I} . \mathrm{V} .=0,19-0,26 \mathrm{~mm})$ de 1 argura.

\subsubsection{LARVA}

Conforme é mostrado no item 4.3.2., esta fase $\underline{a}$ presenta 5 instares, cujos dados de duração e biométricos, de cada instar, estão relatados nas Tabelas 1 e 2 , respectivamente. 


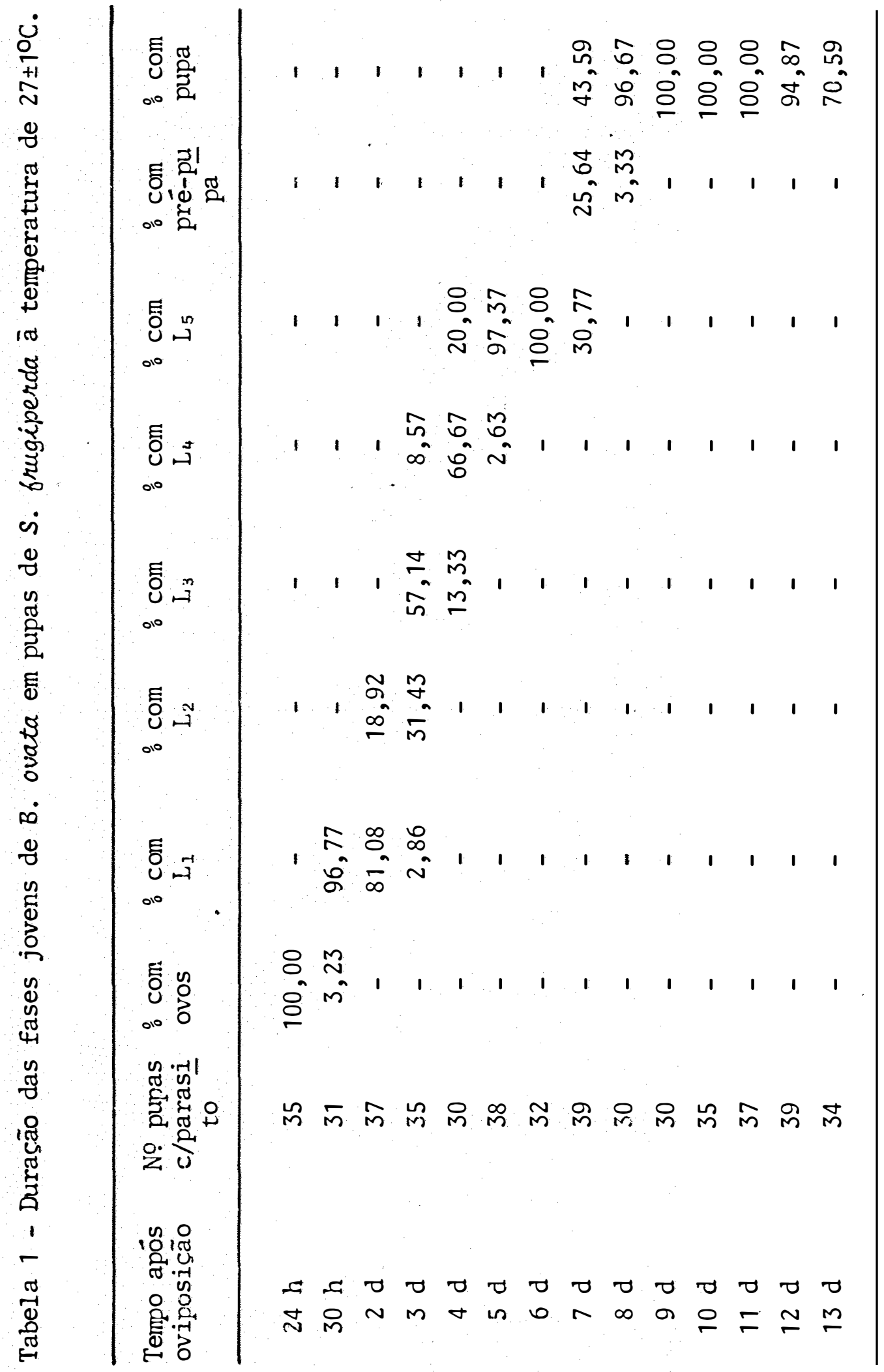


Tabela 2 - Medidas biométricas clos 5 ínstares larvais de B. ovata.

\begin{tabular}{|c|c|c|c|c|c|}
\hline & $\mathrm{J}_{1}$ & $\mathrm{~L}_{2}$ & $\mathrm{~L}_{3}$ & $\mathrm{~L}_{4}$ & $\mathrm{~L}_{5}$ \\
\hline \multicolumn{6}{|l|}{ Diâmetro do espiráculo } \\
\hline - Número de espécinens & 60 & 17 & 24 & 24 & 87 \\
\hline . Média $(\mu)$ & 5,40 & 17,29 & 27,42 & 43,83 & 87,16 \\
\hline - Intervalo de Variação & $4-7$ & $14-22$ & $23-33$ & $37-51$ & $68-93$ \\
\hline \multicolumn{6}{|c|}{ Comprimento da barra tentorial } \\
\hline . Número de espécimes & 59 & 13 & 22 & 23 & 87 \\
\hline - Miédia $\left(10^{-2} \mathrm{~mm}\right)$ & 9,10 & 16,77 & 25,73 & 39,26 & 61,41 \\
\hline . Intervalo de Variação & $7-11$ & $12-21$ & $22-28$ & $31-44$ & $50-70$ \\
\hline \multicolumn{6}{|l|}{ Largura da máscara bucal } \\
\hline . Nünero de espécimens & 60 & 13 & 23 & 22 & 88 \\
\hline . Média $\left(10^{-2} \mathrm{~mm}\right)$ & 8,80 & 14,46 & 20,65 & 28,95 & 40,38 \\
\hline - Intervalo de Variação & $7-10$ & $12-17$ & $19-22$ & $24-32$ & $34-47$ \\
\hline \multicolumn{6}{|l|}{ Cápsula cefälica ou } \\
\hline \multicolumn{6}{|l|}{ largura mäxima da cabeça } \\
\hline - Núnero de espéciniens & 64 & 17 & 25 & 20 & 88 \\
\hline - Média $\left(10^{-2} \mathrm{~mm}\right)$ & 21,19 & 32,41 & 48,68 & 73,55 & 113,52 \\
\hline - Intervalo de Variação & $17-26$ & $28-40$ & $43-59$ & $67-84$ & $95-126$ \\
\hline \multicolumn{6}{|l|}{ Comprimento do corpo } \\
\hline - Núnero de espécimens & 61 & 18 & 24 & 24 & 87 \\
\hline . Média (mun) & 1,53 & 2,15 & 3,17 & 5,07 & 10,42 \\
\hline - Intervalo de Variação & $1,1-2,1$ & $1,3-2,9$ & $2,3-4,3$ & $3,5-7$ & $7-13$ \\
\hline
\end{tabular}


A larva é branco-amarelada e vermiforme (Figuras 4 e 5), muito semelhante à larva de $B$. intermedia estudada por DOWDEN (1935).

A cabeça é bem definida e em forma de cúpula mais ou menos alongada no 19 instar e mais achatada e alargada nos instares posteriores (Figuras 6 e 7 ). Ten um par de reduzí das antenas, 1 par de mandíbulas, máscara bucal, hypostoma e tentório. Esses dois ültimos não são bem nítidos nos 2 primeiros instares, tendo inclusive a barra transversal do tentório fracamente esclerosada (Figura 6) como também ocorre na larva do 19 instar de $B$. intermedia (DOWDEN, 1935). A partir do 39 instar esses caracteres tornam-se mais definidos quando o hypostoma une-se perfeitamente às extremidades da barra transver sal do tentório (Figura 7).

o corpo tem 13 segmentos mais ou menos iguais en comprimento (Figuras 4 e 5 ). 0 sistema traqueal nos 2 primeiros instares tem 4 pares de espiráculos abertos, 1 no mesotórax e os outros nos três primeiros segmentos abdominais e por isso classifica-se no grupo VI de PARKER (1924). Nos demais instares, o sistema traqueal apresenta 9 pares de espiráculo abe tos, cada par sobre: meso- e metatórax e os 7 primeiros segmen tos abdominais.

A larva de b. ovata apresentou o häbito solit $\underline{a}$ rio, pois foi observado em várias pupas superparasitadas que a penas um parasitóide se desenvolveu. A competição pelo nicho 은 correu logo no 1 o ínstar, quando a larva mais forte eliminou 

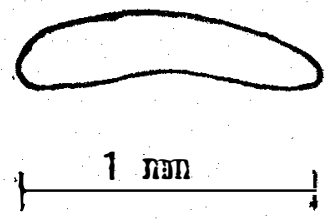

Figura 3 - Ovo de B. ovata em vista lateral.

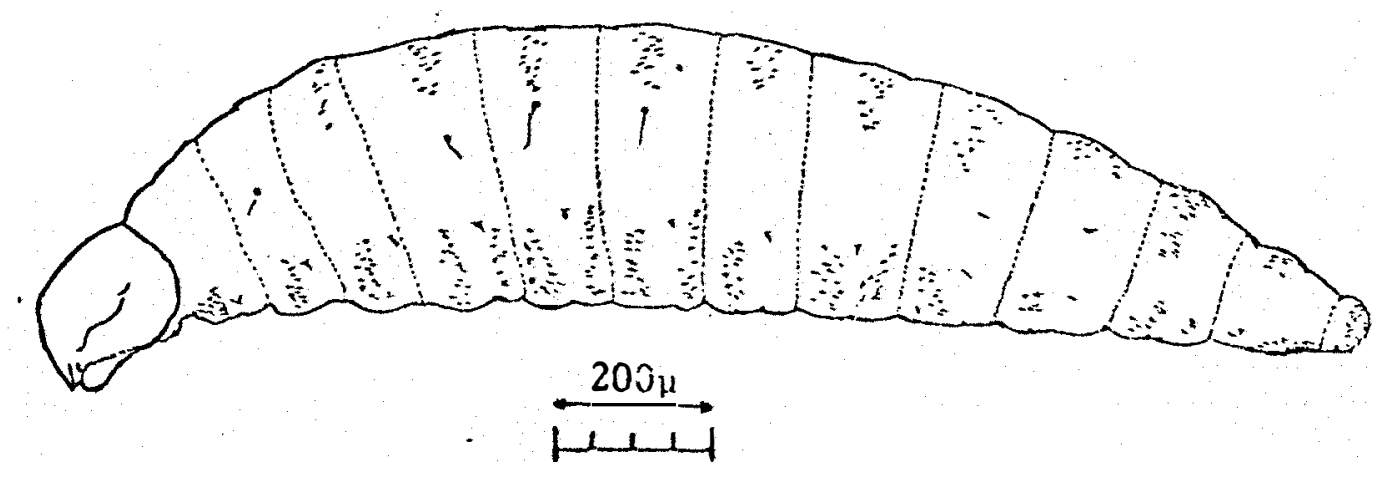

Figura 4 - Larva de B. ovata no 10 instar em vista lateral.

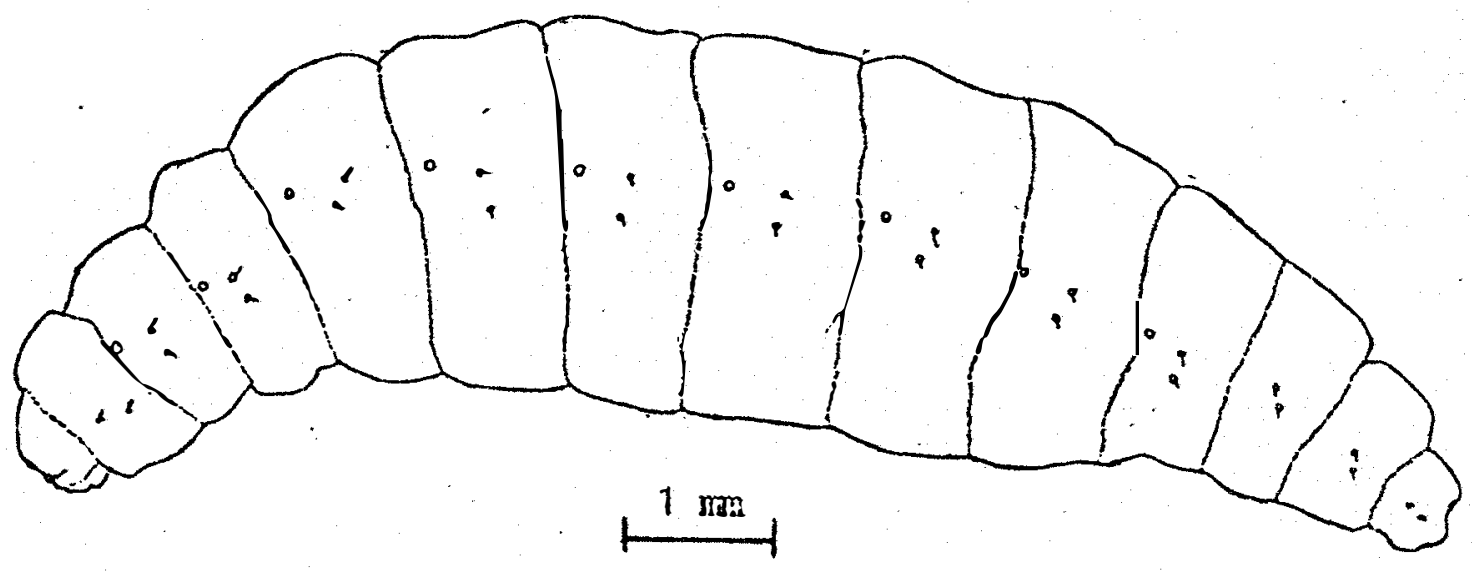

Figura 5 - Larva de $B$. ovata no 5 o instar em vista lateral. 


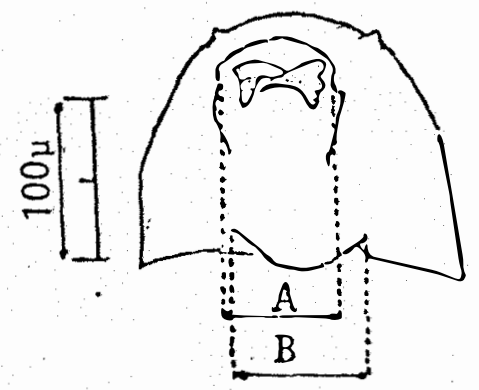

Figura 6 - Cabeça da larva de B. ovata no 19 instar em vista ventral:

A - largura da mäscara bucal

B - comprimento da barra transversal do tentörio

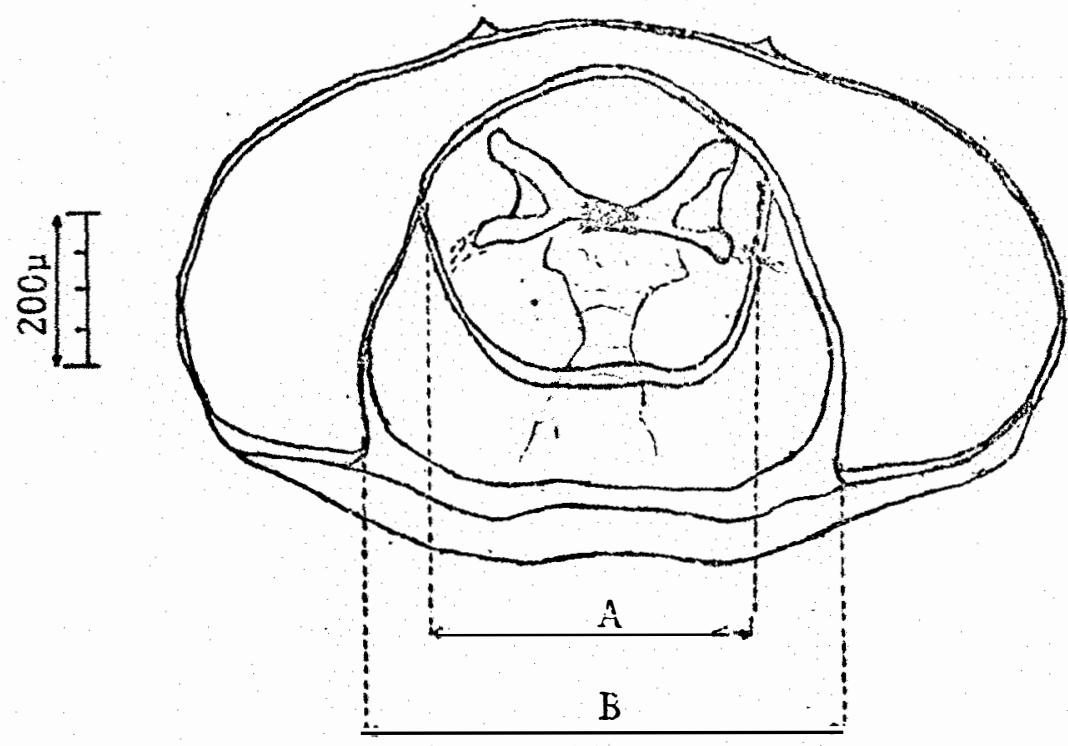

Figura 7 - Cabeça da larva de B. ovata no 5 o instar em vista ventral:

A - largura da náscara bucal

B - comprimento da barra transversal do tentório. 
suas competidoras. Nas larvas mortas às vezes pôde-se perceber a marca de mandíbulas, provavelmente devido à luta com sua con corrente. Esse comportamento é semelhante ao das espécies Brachymeria intermedia e B. compsilurae, relatados por DOWDEN (1935) .

\subsection{PRÉ-PUPA}

A pré-pupa é inteiramente branca e forma-se quando a larva completamente desenvolvida elimina o mecônio, como ocorre com a larva de B. intermedia (DOWDEN, 1935). De acordo com BERTI FILHO (1979), as larvas de himenópteros endoparasitos têm o mesêntero cego; a Iigação mesêntero-proctodeu se dá após o ūltimo instar larval. O tempo de duração da pré-pupa é de aproximadamente 24 horas (Tabela 1 ).

\subsubsection{PUPA}

Tem um tegumento fino e transparente, através do qual pode-se perceber os caracteres do adulto. Essa fase du rou cerca de 6 a 7 dias. No 19 dia é amarelada, mas com o desenvolvimento, a pigmentação torna-se castanha nos 2 e e 30 dias e preta brilhante no 49 dia como na fase adulta. 
Pelas pupas foi possível separar os sexos, atra vés da carena ventral no gaster da fëmea. Observou-se também o dimorfismo sexual pelas dimensões da cápsula cefálica e compri mento do corpo (Tabela 3 ). A análise desses dados (Tabelas 4 e 5), conforme o método citado no item 3.4.3., mostrou que os se xos diferiram estatisticamente ao nível de $1 \%$ de probabilidade. Portanto, as fêmeas são maiores que os machos.

Tabela 3 - Largura da cápsula cefálica e comprimento do corpo em run de pupas (30 machos + 30 fêmeas) de B. ovata.

\begin{tabular}{lcccccc}
\hline & \multicolumn{2}{c}{ Macho } & & \multicolumn{2}{c}{ Fêmea } \\
\cline { 2 - 3 } \cline { 5 - 6 } & Média & I.V. & & Média & I.V. \\
\hline Cápsula cefálica & 1,82 & $1,72-1,86$ & & 2,03 & $1,97-2,07$ \\
Comprimento corpo & 5,89 & $5,65-6,16$ & & 6,45 & $6,21-6,65$ \\
\hline
\end{tabular}

Tabela 4 - Anâlise de variância das medidas de câpsula cefálica $(\sqrt{x+0,9})$ das pupas de B. ovata.

\begin{tabular}{lrccc}
\hline Causas da variação & G.L. & S.Q. & Q.M. & F \\
\hline Sexo & 1 & 0,6032 & 0,6032 & $668,4370^{* *}$ \\
Resỉduo & 58 & $5,2337 \times 10^{-3}$ & $9,0237 \times 10^{-5}$ & \\
\hline Total & 59 & $608,4137 \times 10^{-3}$ & & \\
\hline
\end{tabular}

C.V. $=0,5652^{\circ}$

DMS $=4,9088 \times 10^{-3}$

Niédia cápsula cefálica macho (transformada) $=1,6490$

Média cápsula cefẩlica fêmea (transformada) $=1,7125$ 
Tabela 5 - Anālise da variância do comprimento do corpo $(\sqrt{x+0,6})$ de pu pas de B. ovata.

\begin{tabular}{lrrlll} 
Causas de variação & G.L. & S.Q. & Q.M. & F \\
\hline Sexo & 1 & 0,1711 & 0,171143 & $248,2930^{* *}$ \\
Resíduo & 58 & 0,0400 & $6,8965 \times 10^{-4}$ & \\
\hline Total & 59 & 0,2111 & & \\
\hline
\end{tabular}

C.V. $=1,0093 \%$

DMS $=1,356.5 \times 10^{-2}$

Média comprimento corpo macho (transformada) $=2,5477$

Média comprimento corpo fêmea (transformada) $=2,6445$

\subsubsection{ADULTOS}

\section{- $4: 2.5 \cdot 1$. Aspectos gerais}

A emergência dos adultos de B. ovata à temperatura de $27 \pm 1{ }^{\circ} \mathrm{C}$, ocorreu num período variável de 12 a 19 dias a pós o parasitismo (Tabela 6 ). Os machos emergiram cerca de 1 dia antes das fêmeas.

Em 2167 insetos observados foi encontrada uma relação aproximada de 2 fêmeas: 1 macho, concordando com a mesma proporção obtida por PATANA et alii (1978) em pupas de He- 
leothis zea à $30^{\circ} \mathrm{C}$. Entretanto, ainda nessa temperatura, os autores ob tiveram um grande nūmero de fêmeas resultando numa relação de 16 fêmeas: 1 macho em $H$. virescens mas, por outro lado, em Pectinophora gossypiella, a relação foi de 1 fêma: 7 machos.

As cópulas observadas em 6 casais ocorreram durante o dia, num período variável de $20 \mathrm{~min}$ até $9 \mathrm{~h}$ após a emergência da fêmea, e duraram de 5 a 10 segundos. As fêmeas são uninupciais, pois sempre rejeitaram os machos após a cópula que pareceu ser estimulada, pela exposição do casal ao sol por cerca de 10 minutos.

0 tempo de duração, bem como a "côrte" que ante cede a cópula são muito semelhantes aos das espécies B. intermedia e B. lasus, estudados por LEONARD e RINGO (1978) e SIMSER e COPPEL (1980), respectivamente.

0 período de pré-oviposição foi, em mēdia, 4,5 dias ( $I . V .=1-10$ dias), um pouco menor que o obtido por PATANA em 1979 (6,9 dias e I.V. = 3 e 21 dias).

Foi observado, através de dissecação, que em cada introdução do ovipositor, a fêmea deposita apenas 1 ovo. A duração de cada postura foi de $48 \mathrm{~s}(\mathrm{I} . \mathrm{V} .=20$ a $180 \mathrm{~s})$.

o número de ovos, a produção de prọênie e percentagem de emergência de parasitos por fêmea estão apresentados na Tabela 7 .

A produção de progênie/fêmea copulada $(240,77$ parasitos) se aproximou daquela obtida por PATANA (1979) que foi de 227,2 parasitos/fêmea, tendo o autor utilizado $H$. virescens como hospedeiro. 
Tabela 6 - Ciclo em dias (ovo até emergência do adulto) dos machos e das fêmeas de $B$. ouata desenvolvida em pupas de $S$. frugiperda à tem peratura de $27 \pm 1{ }^{\circ} \mathrm{C}$ e $U R=78 \pm 8 \%$.

\begin{tabular}{|c|c|c|c|c|}
\hline & \multicolumn{2}{|c|}{ Machos } & \multicolumn{2}{|c|}{ Fêmeas } \\
\hline & $\begin{array}{l}\text { Ciclo } \\
\text { (dias) }\end{array}$ & freq. obs. & $\begin{array}{l}\text { Ciclo } \\
\text { (dias) }\end{array}$ & freq. obs. \\
\hline & 12 & 12 & 13 & 20 \\
\hline & 13 & 142 & 14 & 350 \\
\hline & 14 & 218 & 15 & 482 \\
\hline & 15 & 253 & 16 & 497 \\
\hline & 16 & 56 & 17 & 103 \\
\hline & 17 & 8 & 18 & 22 \\
\hline & 18 & 3 & 19 & 1 \\
\hline$\overline{\mathrm{X}}$ & 14,34 & - & 15,26 & - \\
\hline
\end{tabular}

As fêmeas virgens produziram somente machos (Ta bela 7) como também referiu-se pATANA em 1979, demonstrando as sim que os machos são uniparentais, ou seja, originam-se de uma partenogênese do tipo arrenótôca que, de acordo com DOUTT (1959) é exibida pela maioria dos himenópteros parasitos. 


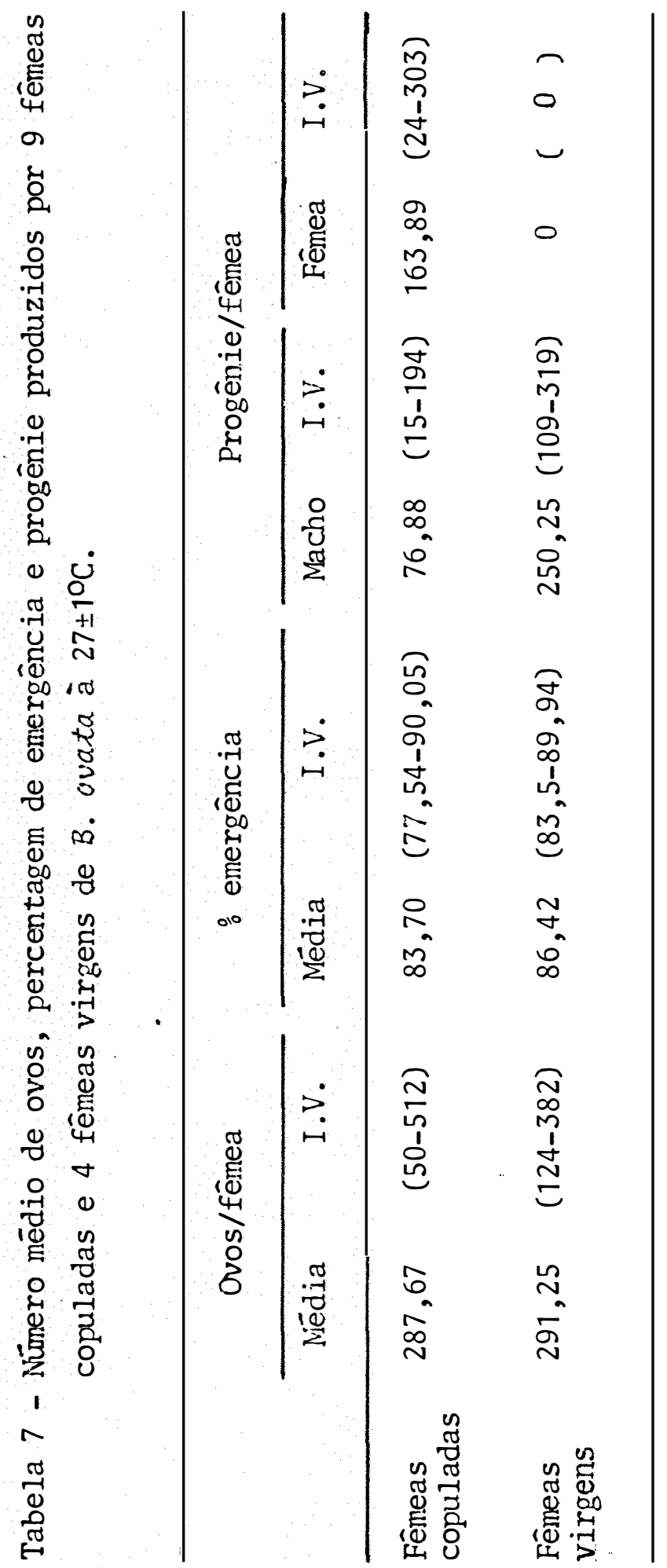


A percentagem de emergência, acima de $80 \%$ (Tabe 1a 7), indicou que $S$. frugiperda $\overrightarrow{\mathrm{e}}$ um bom hospedeiro para a re produção de B. ovata.

0 número de posturas por dia foi muito dependen te dos hospedeiros disponíveis para essa observação, entretanto algumas fêmeas parasitaram até 5 pupas/hora e uma fêmea che gou a fazer 32 posturas num dia, que originaram 30 parasitóides.

A longevidade média à $27 \pm 1{ }^{\circ} \mathrm{C}$ para as fêmeas foi de 65 dias ( $I . V .=6$ a 127 dias) e ficou compreendida entre os dados obtidos por PATANA (1979) para as temperaturas de $25^{\circ} \mathrm{C}$ e $30^{\circ} \mathrm{C}$, respectivamente, 75,9 dias e 49,9 dias. Entretanto a $10 n$ gevidade para os machos igual a 60 dias (I.V. $=35$ a 104 dias) ficou abaixo daqueles obtidos por aquele autor, nas temperaturas discutidas anteriormente.

Os sexos foram diferenciados pela presença de $\underline{u}$ ma carena ventral nos 60 e 79 segmentos do gaster da fêmea e ainda pela extremidade do gaster, aguda ná fêmea e truncada no macho, em vista ventral (Figuras $8 \mathrm{~A}$ e $8 \mathrm{~B}$ ).

Como ocorreu nas pupas, as dimensões da cápsula cefálica e do comprimento do corpo (Tabela 8), também foram ca racteres de dimorfismo sexual, porque o teste $F$ (Tabelas 9 e 10) foi muito significativo para os dois parâmetros analisados. Confirmando-se assim, que as fêmeas são maiores que os ma chos. 

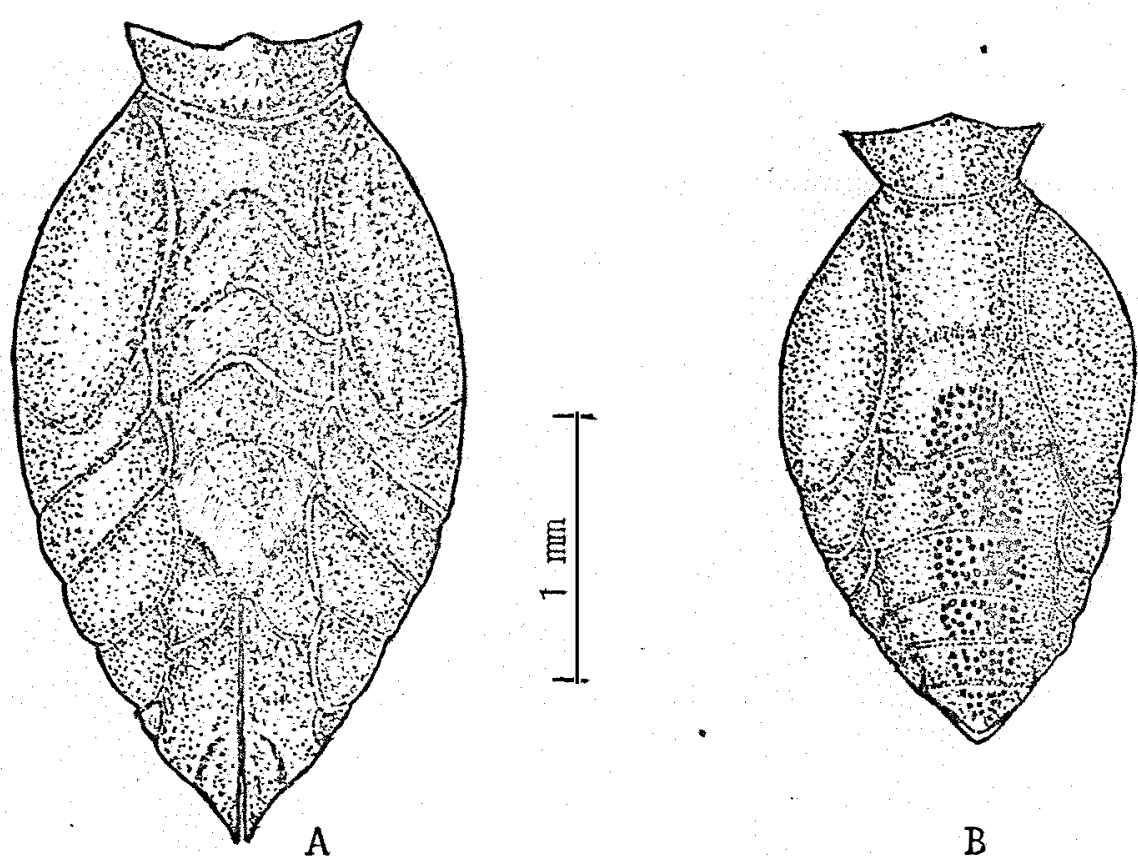

Figura 8 - Vista ventral do abdome de B. ovata: A - fêmea; B - macho.

Tabela 8 - Largura da cāpsula cefâlica e comprimento do corpo em nim de adultos (30 machos + 30 fêmeas) de B. ovata.

\begin{tabular}{|c|c|c|c|c|}
\hline & \multicolumn{2}{|c|}{ Macho } & \multicolumn{2}{|c|}{ Fêmea } \\
\hline & Miédia & I.V. & Média & I.V. \\
\hline $\begin{array}{l}\text { Cápsula } \\
\text { cefälica }\end{array}$ & 1,79 & $1,72-1,86$ & 2,02 & $1,94-2,07$ \\
\hline $\begin{array}{l}\text { Comprimento } \\
\text { corpo }\end{array}$ & 4,92 & $4,54-5,13$ & 5,64 & $5,27-6,04$ \\
\hline
\end{tabular}


Tabela 9 - Análise da variância da cápsula cefálica $(\sqrt{x+0,9})$ de adultos de B. ovata.

\begin{tabular}{|c|c|c|c|c|}
\hline $\begin{array}{l}\text { Causas de } \\
\text { variação }\end{array}$ & G.L. & S.Q. & Q.M. & $F$ \\
\hline Sexo & 1 & $7,0145 \times 10^{-2}$ & $7,0145 \times 10^{-2}$ & $692,5370 * *$ \\
\hline Resỉduo & 58 & $58,7465 \times 10^{-4}$ & $1,012.9 \times 10^{-4}$ & \\
\hline Total & 59 & $7,6019 \times 10^{-2}$ & & \\
\hline \multicolumn{5}{|c|}{ C.V. $=0,6005^{\circ}$} \\
\hline \multicolumn{5}{|c|}{$\mathrm{DMS}=5,1999 \times 10^{-3}$} \\
\hline \multicolumn{5}{|c|}{ Média da cāpsula cefálica do macho (transformada) $=1,6415$} \\
\hline \multicolumn{5}{|c|}{ Média da cápsula cefálica da fêmea (transformada) = 1,7099 } \\
\hline
\end{tabular}

Tabela 10 - Análise da variâricia do comprimento do corpo $(\sqrt{x+0,6})$ de a dultos de B. ovata.

\begin{tabular}{lccll}
\hline $\begin{array}{l}\text { Causas de } \\
\text { variação }\end{array}$ & G.L. & S.Q. & Q.M. & F \\
\hline Sexo & 1 & 0,3312 & 0,3312 & $334,857^{* *}$ \\
Resíduo & 58 & $5,7373 \times 10^{-2}$ & $9,8919 \times 10^{-4}$ & \\
\hline Total & 59 & 0,331811 & \\
\hline
\end{tabular}

C.V. $=1,2974 \%$

DMS $=1,6250 \times 10^{-2}$

Média comprimento corpo do macho (transformada) $=2,3498$

Média comprimento corpo da fêmea (transformada) $=2,4985$ 
As fêmeas tambén diferiram dos machos pela ali.. mentação, porque aquelas além do mel, nutriram-se do fluido que exsuda do hospedeiro após a retirada do ovipositor. De acordo com DOUTT (1959), os himenópteros parasiticos alimentam-se desse fluido para obter proteína necessäria à ovogênese.

\subsubsection{Identificação da espécie}

Os caracteres dos espécimens machos e fêneas e-. xaminados, concordaram com as descrições de BURKS (1960) para a espécie Brachymeria ovata nos seguintes aspectos: tamanho (Tabela 8); inseto em geral preto com tégulas amarelas; antenas geniculadas com 7 segmentos no funículo, mais a clava formada pela fusão dos 3 últimos antenômeros (Figura 9) e inseridas li geiramente acima do nível da margem ventral dos olhos compostos (Figura 10); ápice da cavidade escrobal atingindo o ocelo anterior; mandíbula esquerda com 2 grossos dentes subiguais e a mandíbula direita com 3 dentes, sendo o ventral mais agudo que os demais (Figura 12); carena frontal ausente; sutura malar ou fronto-genial terminando no olho composto e pode apresentar uma pequena carena postorbital que sai da margem da gena em direção da sutura malar, mas não a alcança (Figura 10); cabeça e noto torácico cobertos com pubescência prateada nas fêmeas e dourada nos machos; terço mediano da margem anterior do pronoto sem carena; parte mediana da margem posterior do 


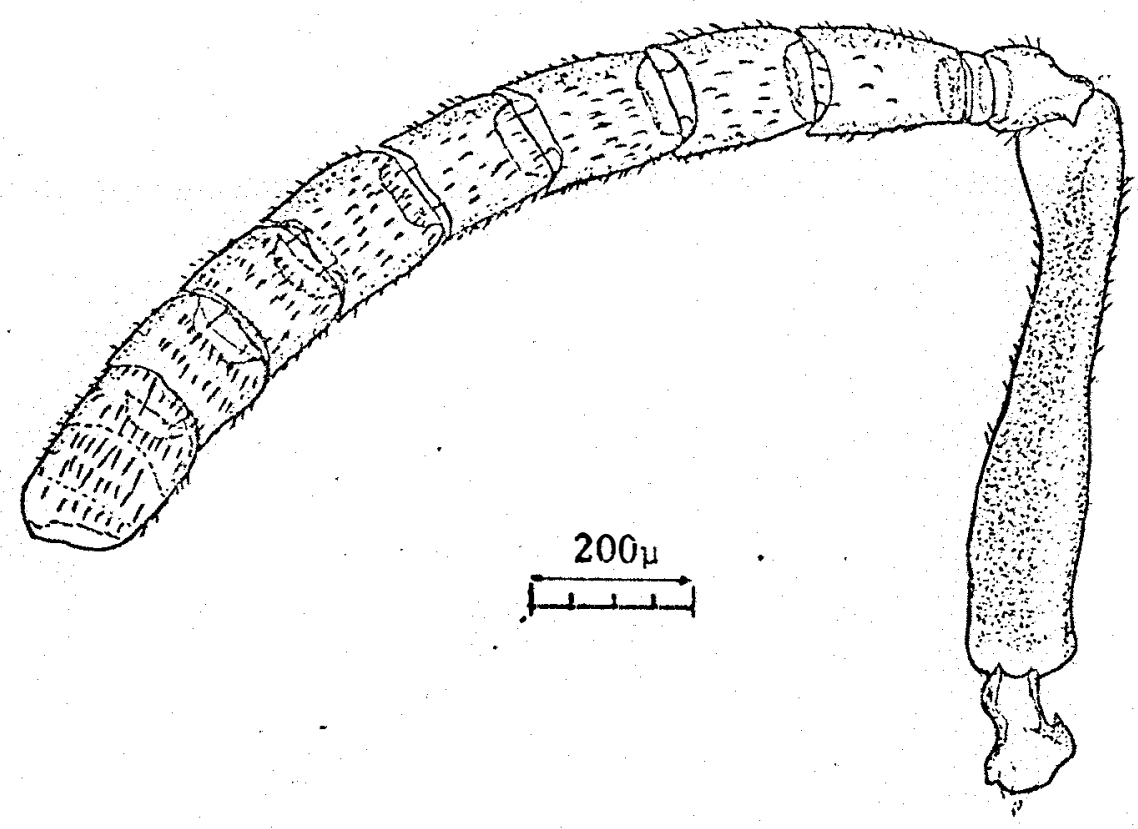

Figura 9 - Antena de B. ovata.

pronoto sem carena transversal; face lateral do pronoto com a margem dorsal interrompida anteriormente, área superior levemente áspera e um sulco oblíquo e raso paralelo à carena que cruza a face lateral do pronoto (Figura 10); intersticios do dorso torácíco punctuados (Figura 11); asa anterior hialina com a veia marginal cerca de 2 vezes mais longa que a pós-marginal e a veia stigmal cerca de $1 / 2$ a $1 / 3$ do comprimento da pós-marginal (Figura 13); escutelo convexo com o ápice inteiro ou arredondado; coxa posterior com um dente mediano (Figura 14); fê mur posterior com a superfície externa pilosa e brilhante, den te basal externo desse fêmur ligeiramente maior que os maiores dentes seguintes, 9 a 12 dentes externos; dentes internos ausentes; superficie dorsal do 19 gaster 1 isa a brijhante; mar- 

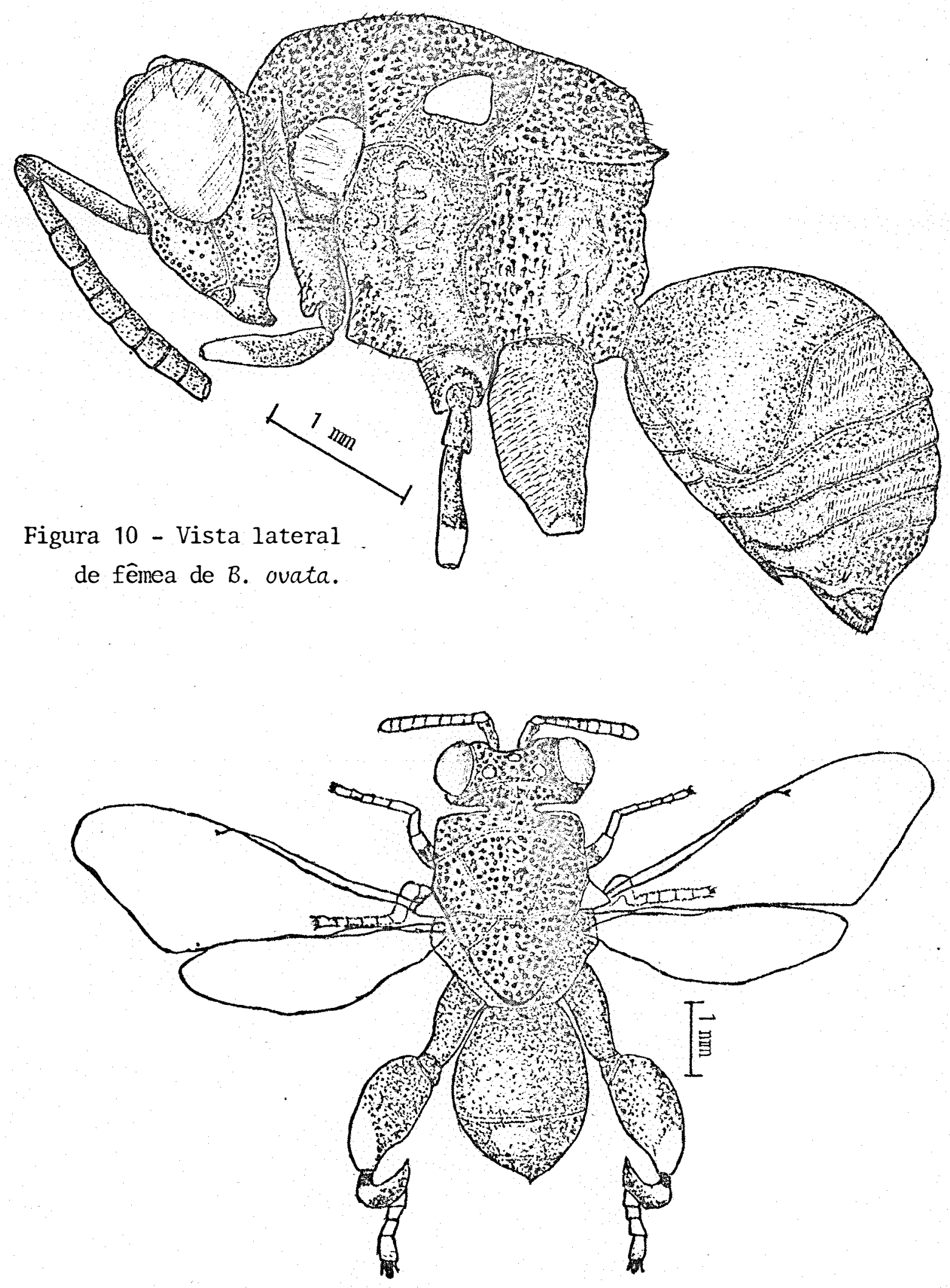

Figura 11 - Vista dorsal da fêmea de B. ovata. 


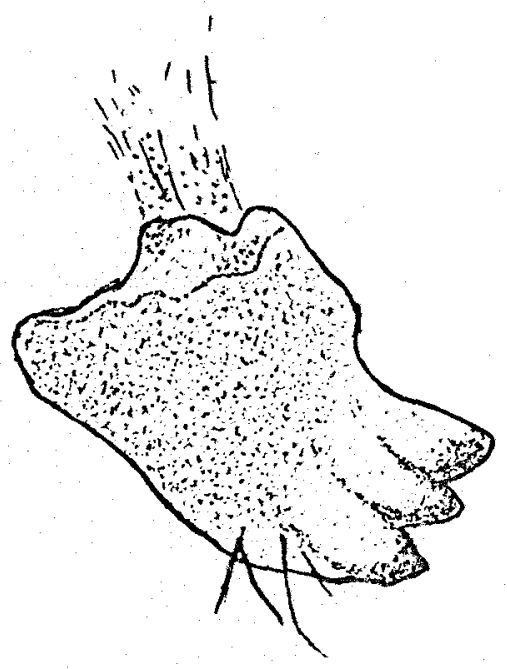

A

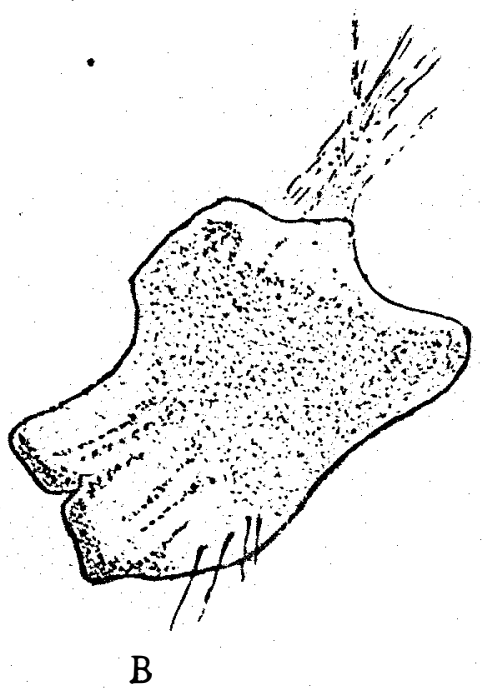

Figura 12 - Mandíbulas de B. ovata em vista dorsal:
A - mandíbula direita
B - mandíbula esquerda

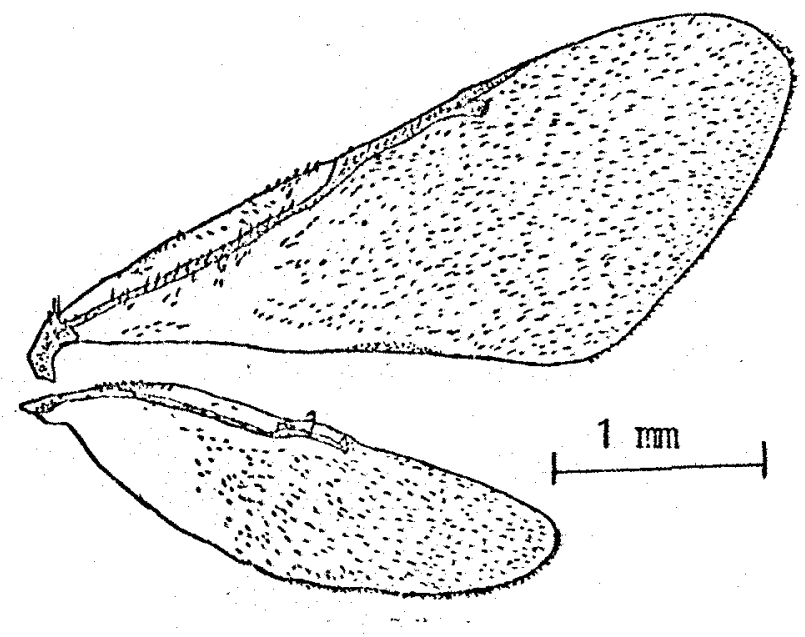

Figura 13 - Asas de B. ovata. 

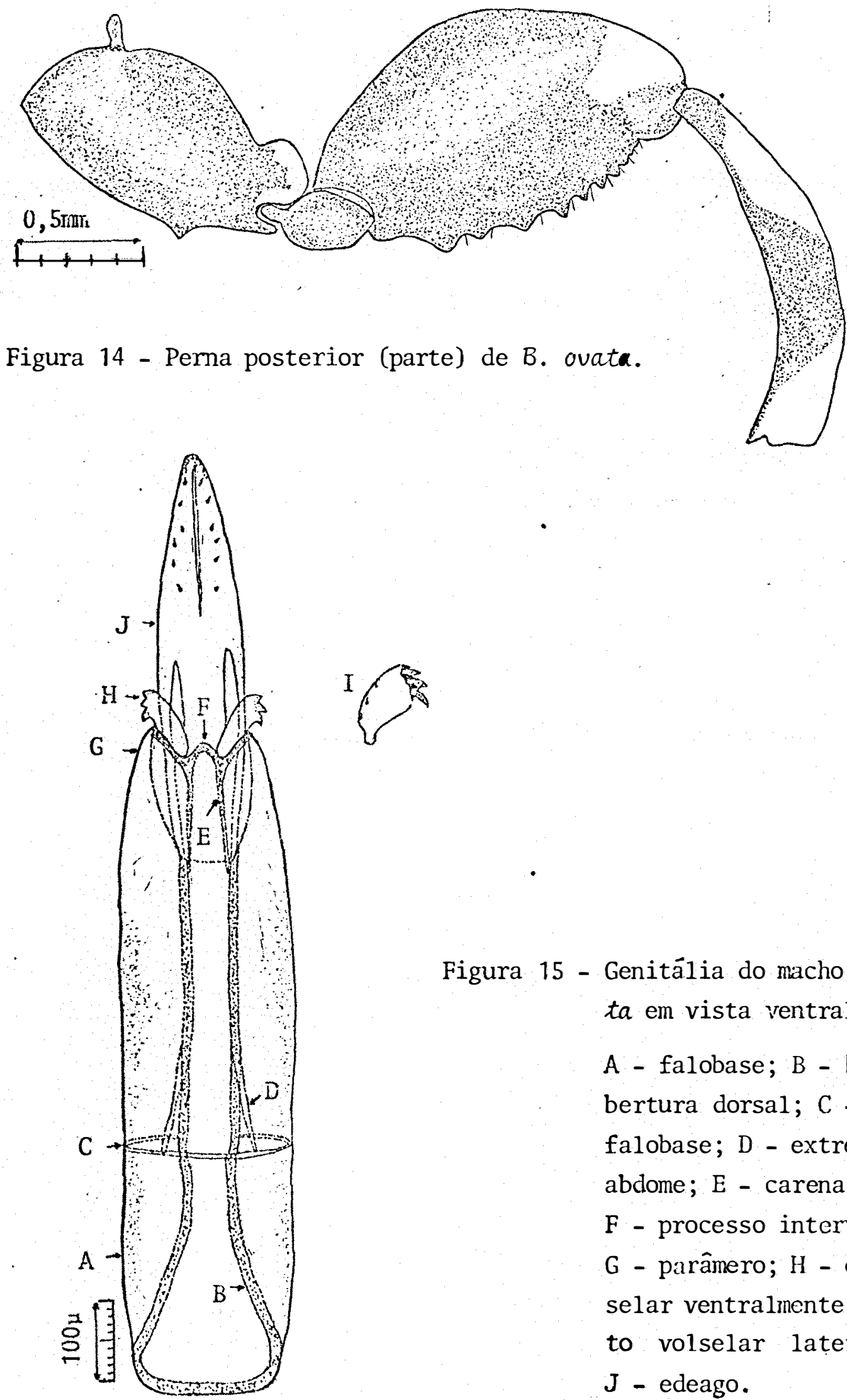

Figura 15 - Genitália do macho de B. ova ta em vista ventral:

A - falobase; B - bordo da a bertura dorsal; $\mathrm{C}$ - anel do falobase; D - extremidade do abdome; E - carena volselar; F - processo intervolselar ; G - parâmero; H - dígito vol selar ventralmente; I - díg $\underline{i}$ to volselar lateralmente ; $\mathrm{J}$ - edeago. 
gem anterior dorsal do segundo segmento do gaster com uma fileira de pêlos que é freqüentemente interrompida na parte mediana, e após esses pêlos existe uma ärea mediana firacamente punctuada; sexto segmento do gaster muito punctuado e piloso; äpice do gaster subtruncado.

Além desses caracteres, o pênis é muito seme-

Thante à figura do mesmo apresentada por BURKS (1936).

Em contraste a toda essa similaridade, foram ob servadas as seguintes diferenças entre os espécimens brasileiros (neotropicais) e os neárticos descritos por BURKS (1936 e 1960):

Neárticos

- todos os fêmures pretos com sonente o äpice amarelo

\section{Neotropicais}

- fêmur anterior com $1 / 2$ a $2 / 3$ basal preto e o restante amarelo, fëmur mëdio com $2 / 3$ basal preto e o restante amarelo, e o fenur posterior preto con o äpice amarelo (Figura 14).

geralmente as tíbias anterior e média são totalmente amarolas, e às vezes existe uma mancha preta na su perficie interna e mediana dessa tíbias

- base e ápice da tíbia posterior ama relos

- base do apódema do edeago alargada em vista dorsal
- mancha preta sempre prescnte na face interna dessas tibias tíbia posterior com base preta e ápice amarelo (Figura 14).

base do apódena do edeago não alargada eni vista dorsal, mas sim em vista lateral (Figuras 16B e 16C)

Essas diferenças provavelmente sejam apenas de ordem subespecifica, como tambëm referiram-se BURKS (1960) e DE SANT IS (1969) . 


\subsubsection{Genitália do macho}

Apesar de BURKS (1960) ter relatado que entre as espécies de Brachymeria, a genitália do macho apresenta diferenças pouco marcantes, estudou-se a genitália do macho para auxiliar a identificação de B. ovata. Assim foram observadas as seguintes características:

- Falobase escle erosada com $0,82 \mathrm{~mm}$ de comprimento por $0,22 \mathrm{~mm}$ de largura. Constituiu-se numa bainha para o edeago, e tem a forma de um bastonete com uma abertura dorsal em toda sua ex tensão. Na parte superior do terço basal, apresenta uma "cin ta ou anel", onde aparentemente apóia-se a extremidade do apódema. Na região superior da falobase encontram-se os parâmeros que apresentam 4 setas dorsais e as extremidades bem esclerosadas e agudas. Ventralmente em contato com a lâmina volselar, existem duas carenas baciliformes e mais ou menos elevadas, denominadas de carenas volselares, que unem-se por um prolongamento mediano e curvo, o processo intervolselar (Figura 15). Em continuação com as carenas volselares, existe um par de dígitos volselares providos com duas fileiras de 3 dentes cada (Figura 15I).

- O edeago é lanceolado e mede cerca de 0,88 mm de comprimento. O corpo do edeago é aberto dorsalmente em toda sua exten sao (Figura 16A). Os apódemas são longos e retos (Figura 16B) de comprimento quase igual ao do corpo do edeago, e lateral- 


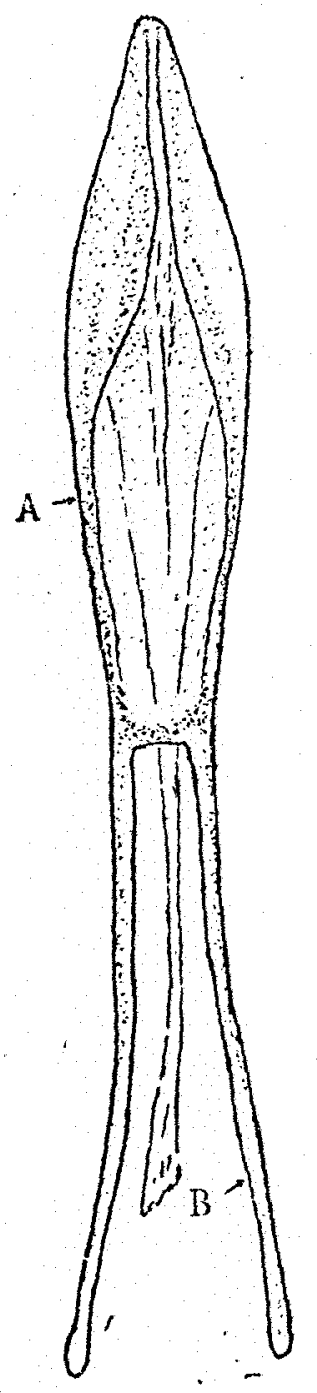

Figura 16 - Edeago de B. ovata em vista dorsal: A - corpo; B - apódema; C - extremi dade do apódema (lateral).
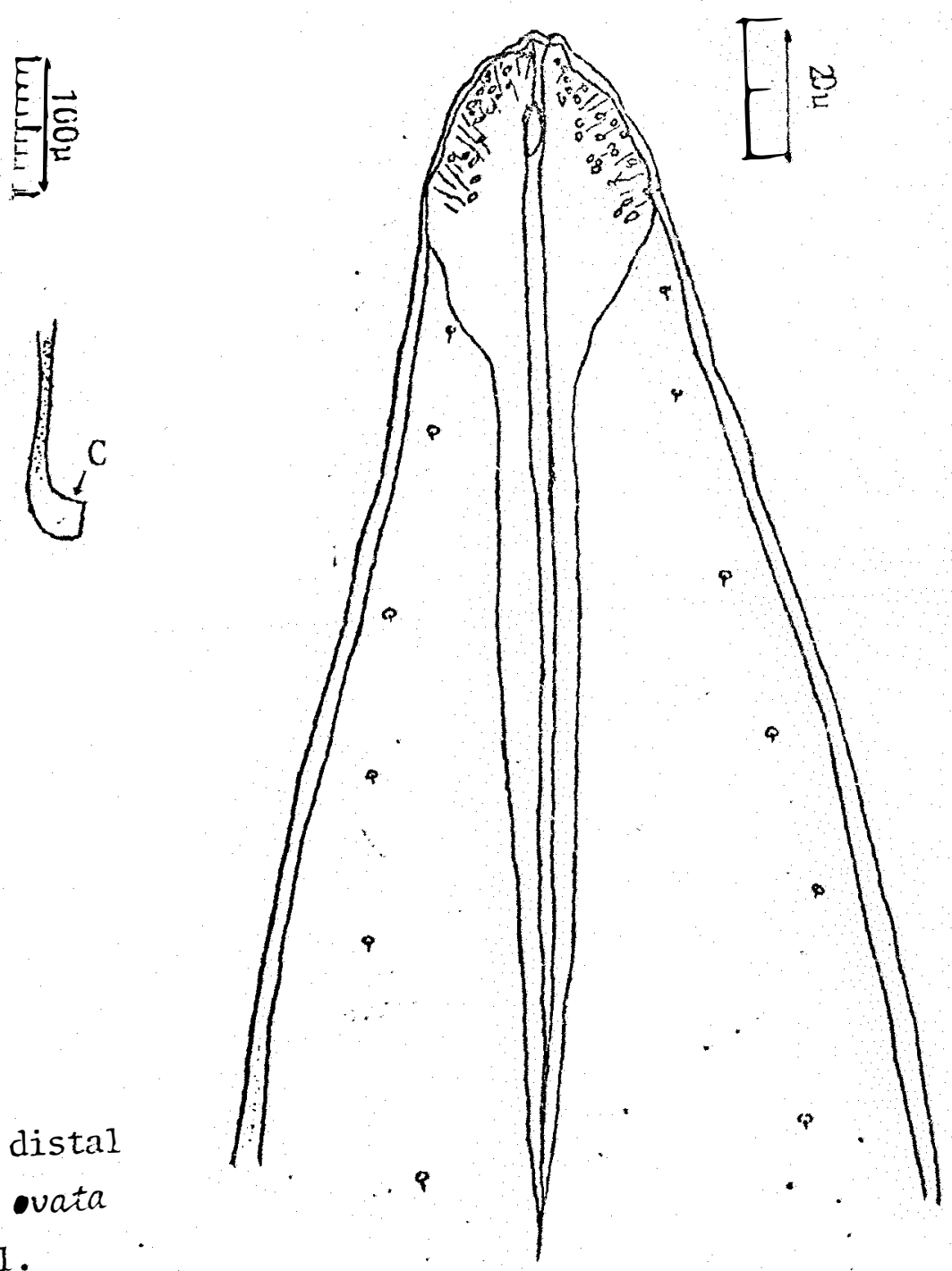

Figura 17 - Parte distal do edeago de 6. ovata em vista ventral. 
mente apresentam as extremidades alargadas (Figura 16C).

- A extremidade do edeago $\vec{e}$ arredondada com estrias e puncturas em todo seu contorno. E dividida longitudinalmente por $\underline{u}$ ma fenda que se estende até quase a metade do corpo do pênis (Figura 17).

\subsection{Métodos para determiniaç̃o do número de instares laR- VAIS DE B. ovata}

\subsubsection{CURVA DE DISTRIBUIÇÃO DE FREQÜENCIA DO DIÂMETRO DO ESPIRÁCULO, COMPRIMENTO DA BARRA TRANSVERSAL DO TENTÓRIO, LARGURA DA MÁSCARA BUCAL E LARGURA DA CÁPSULA CEFÁLICA}

Os diagramas dos dois primeiros parâmetros (Figuras 18 e 19) so definiram bem os grupos extremos, enquanto os intermediārios ficaram muito confusos. Portanto, o espiráculo e a barra transversal do tentório, não foram üteis para indicar'o número de instares por esse método, provavelmente porque os instares intermediārios foram subestimados devido a räpida duração de cada instar (Tabela 1), mas por outro lado, os instares extremos, de maior duração, foram superestimados. 


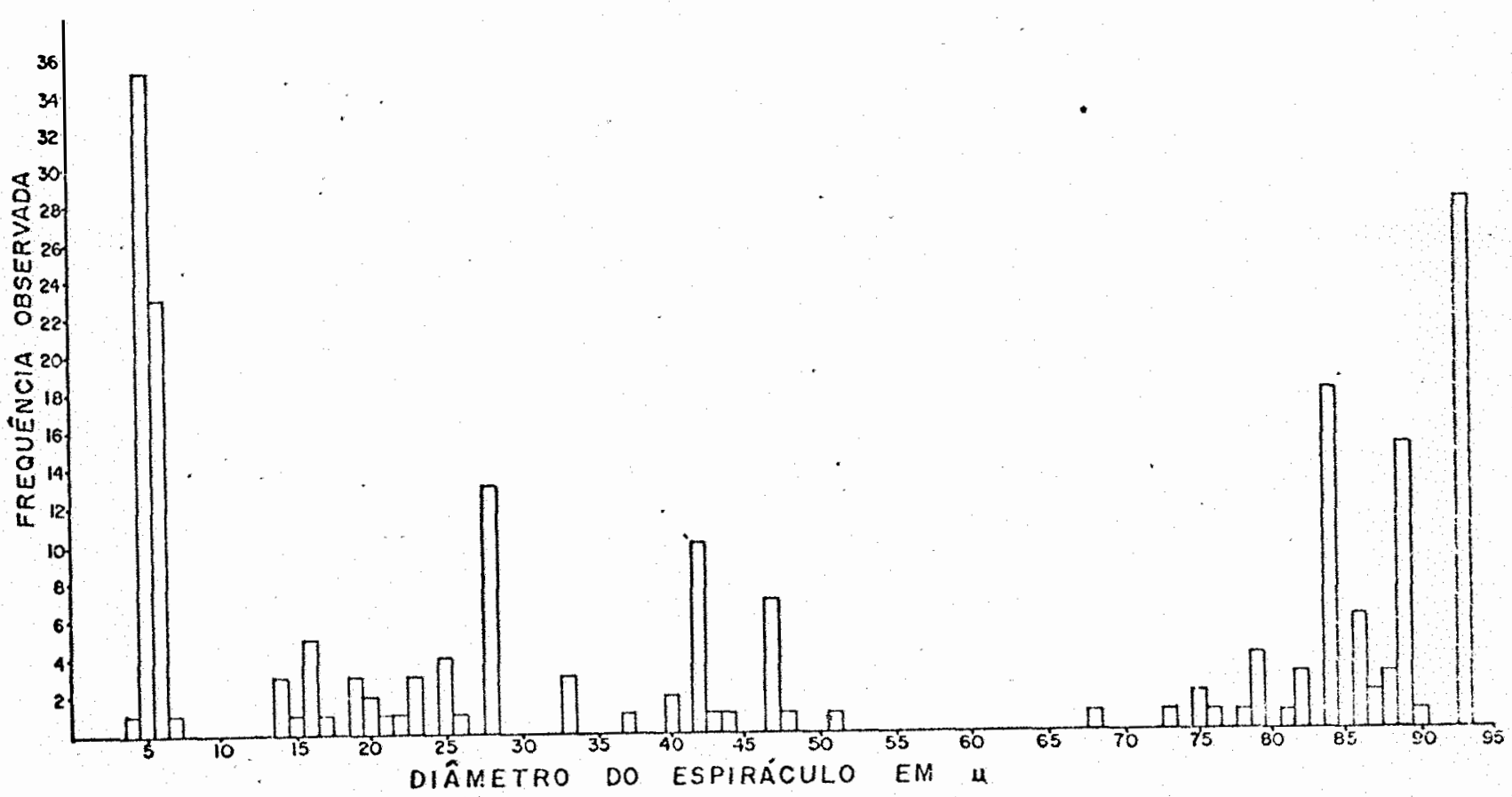

Figura 18 - Distribuição de freqüência do diâmetro do espiráculo ( $\mu$ ) de lar vas de B. ovata.

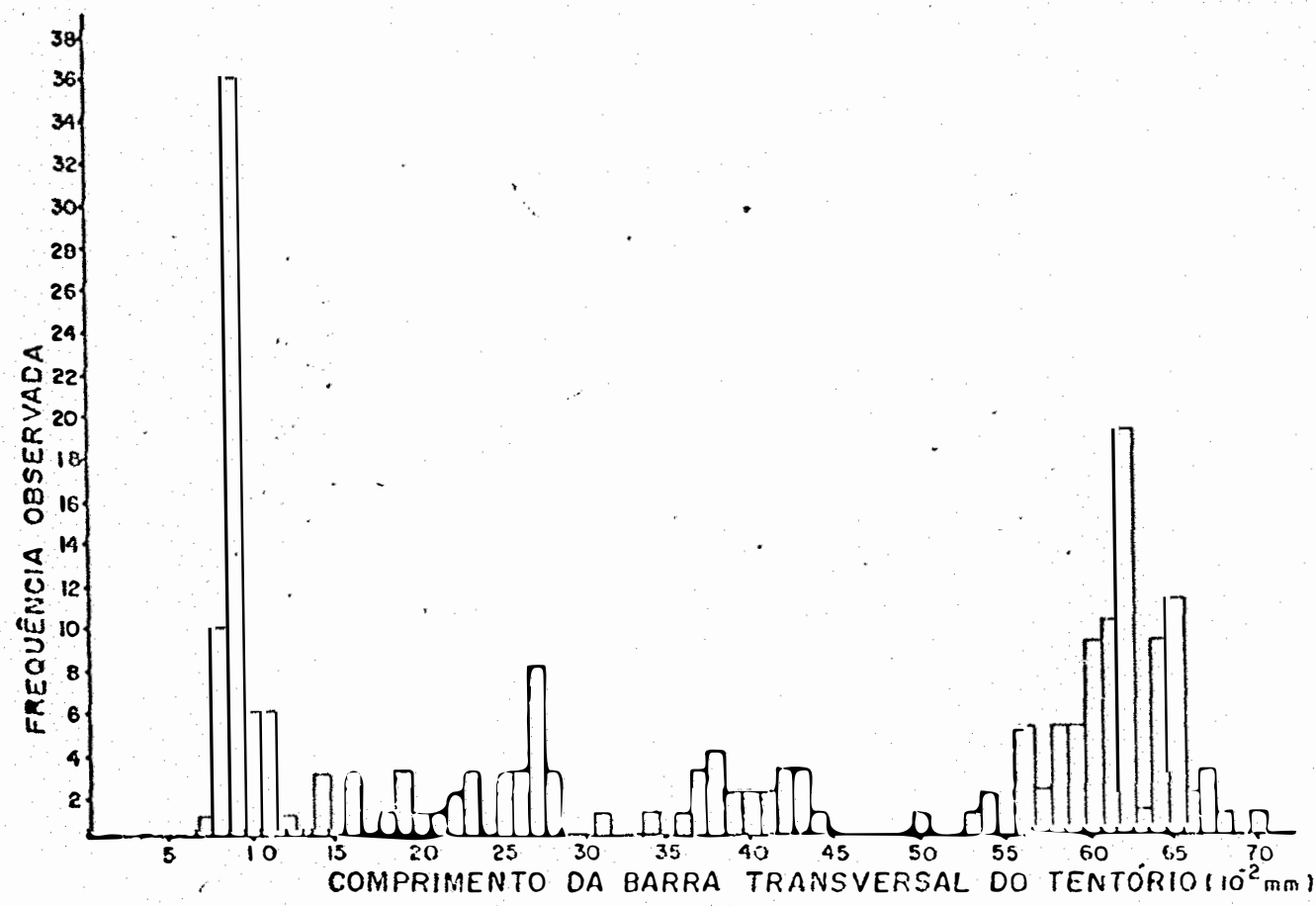

Figura 19 - Distribuição de freqüência do comprimento da barra transversal do tentörio $\left(10^{-2} \mathrm{~nm}\right)$ de larvas de $B$. ovata. 
As larguras da náscara bucal e da cápsula cefálica (Figuras 20 e 21), distinguiram melhor os grupos, inclus ve os intermediários. Entretanto, o nümero de ínstares ficou um pouco indefinido ( 5 ou 6 ), porque o último grupo pôde ser subdividido em dois grupos menores.

\subsubsection{CRESCIMENTO PROGRESSIVO DO DIÂMETRO DO ESPIRÁCU LO, COMPRIMENTO DA BARRA TENTORIAL E LARGIJRA DA MÁSCARA BUCAL}

Os "saltos" no diâmetro dos espiráculos sucessi vos das larvas mortas em ecdise, indicaram ocorrer 5 instares em B. ovata (Tabela 11), porque a ültima ecdise $\left(L_{4}-L_{5}\right)$ eviden ciou que ocorre só um "salto" do grupo 42 a $47 \mu$ para 79 a $93 \mu$, que abrange os dois subgrupos discutidos no item 4.3.1. Por is so, os dados foram distribuídos em 5 grupos ou instares (Tabe1a 12). Os valores médios desse parâmetro, estão muito próximos daqueles obtidos por DOWDEN (1935) para os espiräculos dos 5 instares de $B$. intermedia, que foram respectivamente 6,15 , 23, 40 e $80 \mu$, apesar de serem espécies diferentes. Pode-se ve rificar que o crescimento da barra tentorial e da máscara bucal, também agruparam as larvas de $B$. ovata em 5 instares (Tabela 12). O crescimento simultâneo desses três parāmetros prin cipalmente durante a mudança de ínstar, foi muito útil para es tabelecer os limites dos 5 instares. 


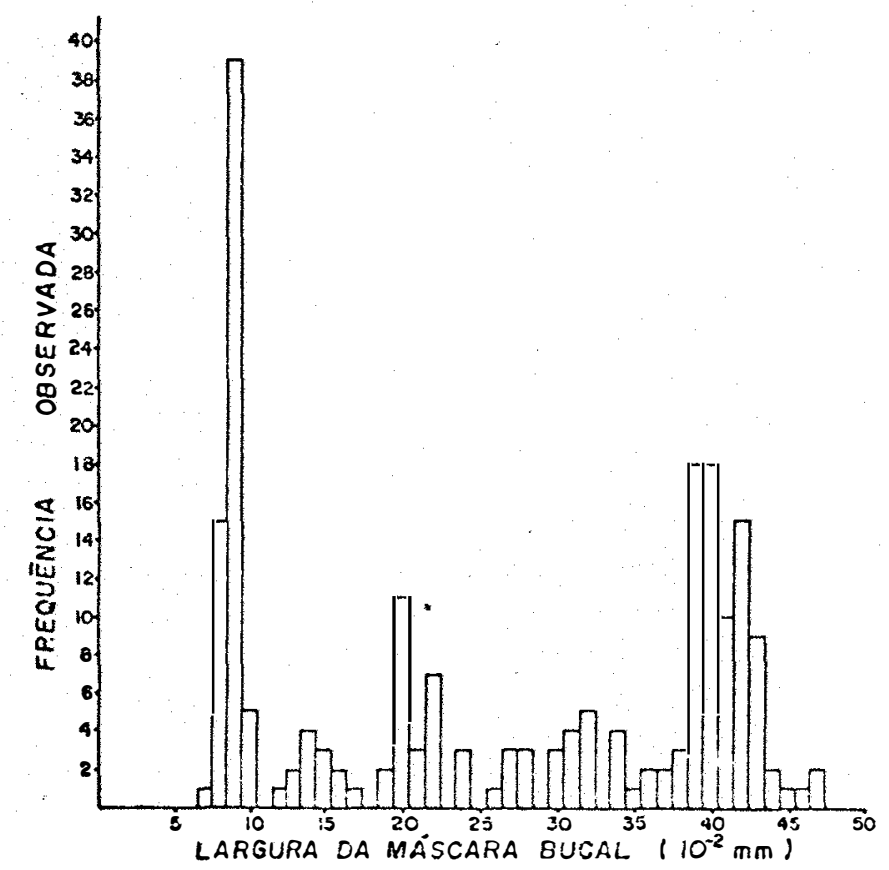

Figura 20 - Distribuição de freqüência da largura da māscara bucal de larvas de B. ovata.

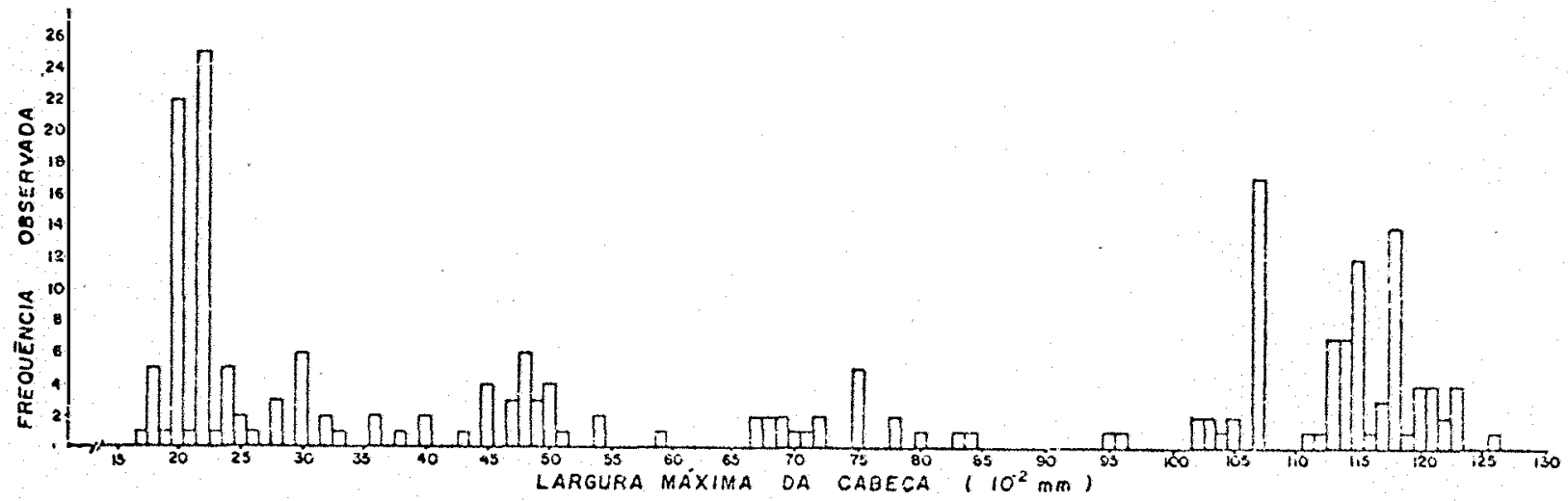

Figura 21 - Distribuição de freqüência da largura máxima da cabeça ou cápsula cefälica de larvas de B. ovata. 
Tabela 11 - Medidas do diâmetro ( $\mu)$ dos espiráculos sucessivos de larvas de B. ovata, mortas durante a ecdise.

$\left(L_{1}-L_{2}\right) \times$ freq. $\quad\left(L_{2}-L_{3}\right) \times$ freq. $\quad\left(L_{3}-L_{4}\right) \times$ freq. $\quad\left(L_{4}-L_{5}\right) \times$ freq.

$\begin{array}{llll}(5-13) \times 3 & (17-28) \times 1 & (25-42) \times 1 & (42-79) \times 1 \\ (5-14) \times 1 & (19-28) \times 1 & (28-42) \times 1 & (42-84) \times 1 \\ (5-15) \times 3 & (19-33) \times 1 & (28-47) \times 1 & (42-86) \times 1 \\ (6-13) \times 1 & (22-30) \times 1 & & (47-89) \times 1 \\ (6-14) \times 1 & & (47-93) \times 1 \\ (6-16) \times 2 & & \end{array}$

Tabela 12 - Médias e intervalo de variação do diânetro do espiráculo $(\mu)$, comprimento da barra transversal do tentório $\left(10^{-2} \mathrm{~mm}\right)$ e largn! ra da máscara bucal $\left(10^{-2} \mathrm{~mm}\right)$ dos 5 instares larvais de $B_{-}$ova ta.

\begin{tabular}{|c|c|c|c|c|c|c|c|c|c|c|c|}
\hline \multirow{2}{*}{ Parametro } & \multirow[b]{2}{*}{$I_{1}$} & \multicolumn{2}{|l|}{$L_{1}$} & \multicolumn{2}{|l|}{$I_{2}$} & \multicolumn{2}{|r|}{ L, } & \multicolumn{2}{|l|}{ Lin } & \multicolumn{2}{|r|}{ Ls } \\
\hline & & $(1, V)$ & & $I_{2}$ & (I.v.) & $I_{3}$ & (I.V.) & $\tau_{4}$ & (I.V.) & $\bar{L}_{5}$ & (I.V.) \\
\hline $\begin{array}{l}\text { Diâmetro do } \\
\text { espiráculo }\end{array}$ & & 5,40 & $(4-7)$ & 17,29 & $(14-22)$ & 27,42 & $(23-33)$ & 43,83 & $(37-51)$ & 87,16 & $(68-93)$ \\
\hline $\begin{array}{l}\text { Barra trans- } \\
\text { versal do } \\
\text { tentório }\end{array}$ & & 9,10 & $(7-11)$ & 16,77 & $(12-21)$ & 25,73 & $(22-28)$ & 39,26 & $(31-44)$ & 61,41 & $(50-70)$ \\
\hline $\begin{array}{l}\text { Mascara } \\
\text { bucal }\end{array}$ & & 8,80 & $(7-10)$ & 14,46 & $(12-17)$ & 20,65 & $(19-22)$ & 28,95 & $(24-32)$ & 40,38 & $(34-47)$ \\
\hline
\end{tabular}




\subsubsection{MÉTODO OBTIDO DA PRÓPRIA REGRA DE DYAR (PARRA E HADDAD， 1983)}

As medidas da cápsula cefálica e da largura da máscara bucal analisadas por esse método, mostraram que ocorre ram 5 e 6 instares nas larvas de B. ovata (Tabelas 13, 14, 15 e 16).

Os valores de $K$ encontrados para esse dois parâa metros, indicaram que tambëm essa espécie segue a regra de Dyar que, de acordo com PARPA e HADDAD (1983), è válida à espécie cujo crescimento progressivo da cápsula cefálica è constante e em média 1,4 (variáve1 de 1,1 a 1,9 ).

Tabela 13 - Médias observada e estimada $(y=2,6378+0,4173 . X)$ e interva10 de variasão da cápsula cefálica de larvas de B. cuata consi derando-se 5 ínstares.

\begin{tabular}{cccc}
$\begin{array}{c}\text { Instares } \\
\left(x_{i}\right)\end{array}$ & Cäp. cef. obs. $\left(10^{-2} \mathrm{~mm}\right)$ & I.v. $\left(10^{-2} \mathrm{~mm}\right)$ & Cáp. cef. est. $\left(10^{-2} \mathrm{~mm}\right)$ \\
\hline 1 & 21,1875 & $17-26$ & 21,2233 \\
2 & 32,4118 & $28-40$ & 32,2140 \\
3 & 48,6800 & $43-59$ & 48,8962 \\
4 & 73,5500 & $67-84$ & 74,2175 \\
5 & 113,5227 & $95-126$ & 112,6516 \\
\hline
\end{tabular}

$$
\begin{aligned}
& K=1,5178 \\
& R^{2}=99,97 \%
\end{aligned}
$$


Tabela 14 - Médias observada e estimada $(y=2,8808+0,3338 . X)$ e interva10 de variação da cápsula cefálica de larvas de B. ovata consi derando-se 6 instares.

\begin{tabular}{cccc}
$\begin{array}{c}\text { Instares } \\
\left(\mathrm{x}_{\mathrm{i}}\right)\end{array}$ & Cáp. cef. obs. $\left(10^{-2} \mathrm{mmn}\right)$ & I.V. $\left(10^{-2} \mathrm{~mm}\right)$ & $\begin{array}{c}\text { Cáp. cef. est. }\left(10^{-2} \text { mon }\right) \\
\left(\hat{\mathrm{y}}_{i}\right)\end{array}$ \\
\hline 1 & 21,1875 & $17-26$ & 24,8933 \\
2 & 32,4118 & $28-40$ & 34,7577 \\
3 & 48,6800 & $43-59$ & 48,5309 \\
4 & 73,5500 & $67-84$ & 67,7619 \\
5 & 105,1538 & $95-107$ & 94,6135 \\
6 & 117,0322 & $111-126$ & 132,1054 \\
\hline$K=1,3963$ & & & \\
$\mathrm{R}^{2}=96,75^{\circ}$ & & &
\end{tabular}

Tabela 15 - Nédias observada e estimada $(y=1,9926+0,3484 . x)$ e intervalo de variação cia largura da máscara bucal de larvas de $B$. ova ta considerando-se 5 ínstares.

\begin{tabular}{lccc}
$\begin{array}{c}\text { Instares } \\
\left(\mathrm{x}_{\mathbf{i}}\right)\end{array}$ & Cáp. cef. obs. $\left(10^{-2} \mathrm{~mm}\right)$ \\
$\left(\mathrm{y}_{\mathbf{i}}\right)$ & I.V. $\left(10^{-2} \mathrm{~mm}\right)$ & $\begin{array}{c}\text { Cäp. cef. est. }\left(10^{-2} \mathrm{~mm}\right) \\
\left(\hat{\mathrm{y}}_{\mathbf{i}}\right)\end{array}$ \\
\hline 1 & 8,8000 & $7-10$ & 10,3916 \\
2 & 14,4615 & $12-17$ & 14,7228 \\
3 & 21,0385 & $19-24$ & 20,8593 \\
4 & 30,6667 & $26-35$ & 29,5534 \\
5 & 40,7470 & $36-47$ & 41,8713 \\
\hline $\mathrm{K}=1,4168$ & & & \\
$\mathrm{R}^{2}=99,56 \%$ & & &
\end{tabular}


Tabela 16 - lédias observada e estimada $(y=2,2010+0,2776 . X)$ e interva1o de variação da largura da máscara bucal de larvas de B. ova ta considerando-se 6 instares.

\begin{tabular}{cccc}
\hline $\begin{array}{c}\text { Instares } \\
\left(x_{i}\right)\end{array}$ & Cáp. cef. obs. $\left(10^{-2}\right.$ rimi $)$ & I.V. $\left(10^{-2}\right.$ mmn $)$ & $\begin{array}{c}\text { Cáp. cef. est. }\left(10^{-2} \text { mon }\right) \\
\left(\hat{y}_{i}\right)\end{array}$ \\
\hline 1 & 8,8000 & $7-10$ & 11,9245 \\
2 & 14,4615 & $12-17$ & 15,7399 \\
3 & 21,0385 & $19-24$ & 20,7760 \\
4 & 30,6667 & $26-35$ & 27,4235 \\
5 & 39,1163 & $36-40$ & 36,1979 \\
6 & 42,5000 & $41-47$ & 47,7796 \\
\hline$K=1,3200$ & & & \\
$R^{2}=95,11 \%$ & & &
\end{tabular}

Pelos valores de $R^{2}$ (maiores que $95 \%$ ), pode-se verificar um ótimo ajustamento do modelo matemático aos dados observados, validando assini as duas hipóteses formuladas. Tal validação ocorreu provavelmente devido ao fator sexo que diferenciou as larvas do último instar pelo tamanho, como se obser vou entre as pupas e adultos, demonstrados nos itens 4.2.4. e 4.2.5.1. De acordo com PATANA et alii (1978), o tamanho do adulto de B. ovata é dependente da nutrição larval e, como as fêmeas (pupas e adultos) são maiores que os machos, torna-se muito provável que isso também ocorra entre as larvas,prin cipalmente no último instar quando as larvas apresentarammaior 
atividade metabólica (item 4.7.1.) e um maior crescimento do comprimento do corpo (Tabela 2). Essa necessidade de acunular matéria para as fases seguintes, provavelmente aumenta a diferença entre os sexos.

\subsubsection{TESTE DE TUKEY}

Os dados do diâmetro do espiráculo analisado por esse método (Tabelas $17,18,19$ e 20), demonstraram tambēm ocorrer 5 e 6 instares nas larvas de B. ovata. Entretanto, é nui to provável que esse parâmetro também sofra influência do sexo, como foi discutido no iten anterior.

Tabela 17 - Análise da variância do diâmetro do espiráculo em $\mu$ de 8 . cua$t a$, considerando-se 5 instares larvais.

\begin{tabular}{lcccc}
$\begin{array}{l}\text { Causas de } \\
\text { variação }\end{array}$ & G.L. & S.Q. & Q.M. & F \\
\hline Tratamentos & 4 & 268588,9070 & 67147,2268 & $4323,53^{* *}$ \\
Resíduo & 207 & 3214,8425 & 15,5306 & \\
\hline Total & 211 & 271803,7500 & 67262,7574 &
\end{tabular}

C.V. $=8,4297^{\circ}$ 
Tabela 18 - Número de espécimens observada(s), intervalo de variação e com paração das médias cio iiânetro do espiráculo em $\mu$ pelo teste de Tukey, considerando-se 5 instares larvais em B. ouata.

\begin{tabular}{cccc}
\hline Instares & $\mathrm{n}$ & I.V. & $\begin{array}{c}\text { Médias }(\text { teste de Tukey*) } \\
(\mu)\end{array}$ \\
\hline 1 & 60 & $4-7$ & $5,400 \mathrm{a}$ \\
2 & 17 & $14-22$ & $17,2941 \mathrm{~b}$ \\
3 & 24 & $23-33$ & $24,4167 \mathrm{c}$ \\
4 & 24 & $37-51$ & $43,8333 \mathrm{~d}$ \\
5 & 87 & $68-93$ & $87,1609 \mathrm{e}$ \\
\hline
\end{tabular}

*ao nível de $1 \%$ de probabilidade.

Tabela 19 - Análise da variância do diâmetro do espiráculo em $\mu$ de $B$. ovata, considerando-se 6 instares larvais.

\begin{tabular}{lrrrr}
$\begin{array}{l}\text { Causas da } \\
\text { variação }\end{array}$ & G.L. & S.Q. & Q.M. & F \\
\hline Tratamentos & 5 & 261404,3430 & 52280,8686 & $8025,42^{\star *}$ \\
Resíduo & 201 & 1309,3960 & 6,5144 & \\
\hline Total & 206 & 262713,7390 & 52287,3830 & \\
\hline
\end{tabular}

C.V. $=5,6086^{\circ}$ 
Tabela 20 - Nümero de espécimens observadas (n), intervalo de variação, e comparação das médias do diâmetro do espiráculo em $\mu$ pelo tes te de Tukey, considerando-se 6 instares larvais em B. ovata.

\begin{tabular}{cccc} 
Instares & $\mathrm{n}$ & I.V. & $\begin{array}{c}\text { Médias (teste de Tukey*) } \\
(\mu)\end{array}$ \\
\hline 1 & 60 & $4-7$ & $5,4000 \mathrm{a}$ \\
2 & 17 & $14-22$ & $17,2941 \mathrm{~b}$ \\
3 & 24 & $23-33$ & $27,4167 \mathrm{c}$ \\
4 & 24 & $37-51$ & $43,8333 \mathrm{~d}$ \\
5 & 38 & $68-86$ & $81,2500 \mathrm{e}$ \\
6 & 49 & $87-93$ & $91,1633 \mathrm{f}$
\end{tabular}

* ao nível de $1 \%$ de probabilidade.

\subsubsection{COMPARACÃO DOS MÉTODOS PARA DETERMINACÃO DO MÚ- MERO DE INSTARES}

0 método da curva de distribuição de freqüência, apesar de apenas indicar os possiveis nümeros de instares, auxiliou todos os outros métodos para limitar cada grupo de indi vỉduos.

Tecnicamente o crescimento do diâmetro do espiráculo foi o método de maior precisão porque, além de diferenciar os 5 instares pelos "saltos" em seu diâmetro, também possibilitou separar o 29 do 39 instar, pelo número de espirácu- 
los abercos (item 4.2.2.). Essas vantagens, concordam com o trabalho de ROJAS-ROUSSE e BENOIT (1977) onde afirmam que, na maioria das espécies de Hymenoptera parasitos, os fatores que são usados mais freqüentemente para distinguir os instares lar vais são: o aparecimento de espiráculos abertos, o crescimento das traquéias em direção aos espiráculos e o crescimento dos espiráculos abertos. Por outro lado, esse método é muito exigente em tempo e recursos técnicos para a preparação de lâminas e observações microscópicas.

O método obtido da própria regra de Dyar por PARRA e HADDAD (1983), aplicado à cápsula cefálica, foi o ma is prático porque exigiu menor tempo e maior facilidade nas obser vações, entretanto foi menos preciso que o anterior, pela dualidade de interpretação quanto ao nümero de instares. Esse metodo aplicado à máscara bucal tem o inconveniente da preparação microscópica e a mesma imprecisão da cápsula cefálica.

\subsection{CICLO EM TEMPERATURAS CONSTANTES}

O tempo exigido por B. ovata desde a oviposição até a emergência dos adultos, variou de 11,12 dias à $32^{\circ} \mathrm{C}$ até 53,93 dias à $18^{\circ} \mathrm{C}$ (Tabela 21), verificando-se assim que a temperatura afetou intensamente o desenvolvimento desse parasitói de (Figura 22). 0 ciclo médio sob as temperaturas de 20,25 e $30^{\circ} \mathrm{C}$, bem como a faixa de temperatura ótima, foram semelhantes 
aos obtidos por PATANA et alii (1978) (Tabeia 22.), apesar da diferença de hospedeiros. A faixa de $25^{\circ} \mathrm{C}$ à $30^{\circ} \mathrm{C}$, foi considerada como ótima, considerando-se o nümero de descendentes/fêmea/geração e tambēm porque essa espécie se comportou muito bem no estudo da biologia (item 4.2.), quando a temperatura foi de $27 \pm 1{ }^{\circ} \mathrm{C}$.

Tabela 21 - Ciclos observados e estimados em dias, intervalo de variação, percentagem de emergência e número de descendentes/fêmea/gera-. ção de $B$. ovata desenvolvida em pupas de $S$. frugiperda sob 6 temperaturas constantes e $14 \mathrm{~h}$ de fotofase.

\begin{tabular}{|c|c|c|c|c|c|c|}
\hline $\begin{array}{l}\text { Temperaturas } \\
\text { (OC) }\end{array}$ & 18 & 26 & 22 & 25 & 30 & 32 \\
\hline Ciclo obs. (dias) & 53,93 & 31,30 & 27,35 & 17,40 & 12,57 & 11,12 \\
\hline Ciclo est. (dias) & 51,23 & 33,76 & 25,18 & 18,23 & 12,48 & 11,09 \\
\hline Interv. variação & $49-61$ & $26-38$ & $25-32$ & $15-21$ & $11-16$ & $10-12$ \\
\hline \% emergência & 48,33 & 71,66 & 75,00 & 86,67 & 93,33 & $8 \tilde{3}, 33$ \\
\hline 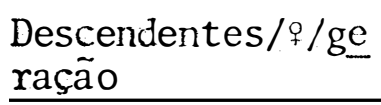 & 92,51 & $13 \ddot{8}, 77$ & 144,55 & 167,68 & 179,25 & 159,97 \\
\hline
\end{tabular}

As estimativas da faixa ótima de desenvolvimento e do limite superior de desenvolvimento pelo método de SAVESCU (1965) não foram aceitas para essa espécie, porque foram muito discrepantes com aqueles observado experimentalmente.

Para a multiplicação desse parasito, a temperatura de $30^{\circ} \mathrm{C}$ parece ser melhor que $25^{\circ} \mathrm{C}$, porque o ciclo foi mais rápido e apresentou a maior percentagem de emergência. 


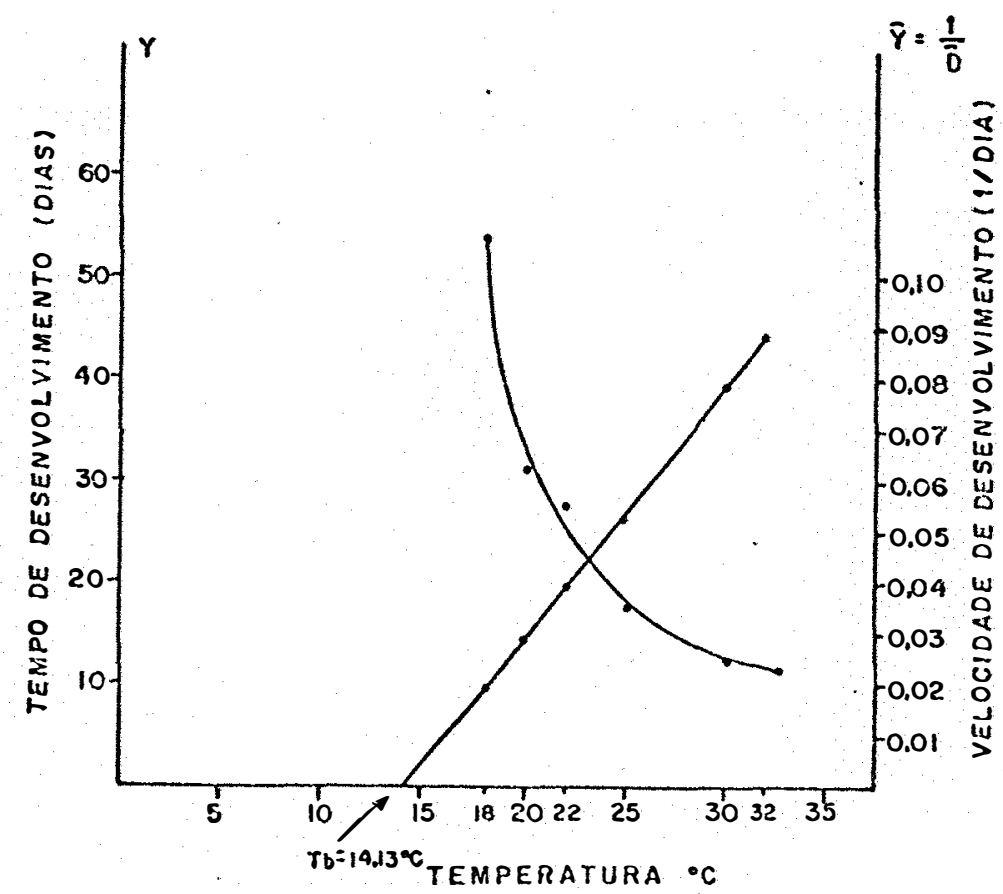

Figura 22 - Relação entre o tempo de desenvolvimento (dia) e a velocidade cie desenvolvimento (1/dia) de B. ovata em fun cão da temperatura.

Tabela 22 - Ciclo en dias (média dos 2 sexos) de B. ovata en 6 hospedeiros sob 4 temperautaras constantes observados por PATANA et alii (1978).

\begin{tabular}{lllll}
\hline Hospedeiro & $20^{\circ} \mathrm{C}$ & $25^{\circ} \mathrm{C}$ & $30^{\circ} \mathrm{C}$ & $35^{\circ} \mathrm{C}$ \\
\hline Trichoplusia ni & 29,39 & 17,76 & 12,81 & 11,86 \\
Stigemene acrea & 30,32 & 18,16 & 13,50 & 12,84 \\
Heliothis virescens & 31,83 & 18,44 & 13,15 & 12,32 \\
Heliothis zea & 32,88 & 19,78 & 14,17 & 12,66 \\
Spodoptera exigua & 29,83 & 17,13 & 13,19 & 11,84 \\
Pectinophora gossypiella & 25,30 & 16,06 & 10,84 & 10,51 \\
\hline
\end{tabular}


4.5. Temperatura base $\left(T_{b}\right)$ e cCnstante térmica $(K)$ DE B. ovata

A temperatura base e a constante térmica para B. ovata desenvolvida em $S$. frugiperda, determinados pelo méto do da hipérbole, foram respectivamente $14,13^{\circ} \mathrm{C}$ e 198 GD (Figura 22 e Tabela 23). O resultado da temperatura base se aproxima muito da observação de PATANA e.t alii (1978), onde relataram que a temperatura de $15^{\circ} \mathrm{C}$ está pröxima do limite inferior de desenvolvimento, porçue poucos adultos emergiram resta temperatura.

Tabela 23 - Temperatura base $\left(\mathrm{T}_{\mathrm{b}}\right)$ e constante térmica $(\mathrm{K})$ estimaço pe jo mê todo da hipérbole para B. ovata desenvolvida em 7 hospecleiros diferentes.

Hospedeiro

$\mathrm{T}_{\mathrm{b}}\left(\mathrm{O}^{\mathrm{C}}\right)$

$K(G D)$.

Spodoptera frugiperda

14,13

198,0

Spodoptera exigua

8,98

293,7

Trichoplusia ni

9,20

289,6

Stigemene acrea

7,98

325,3

Heliothis virescens

9,75

292,3

Heliothis zea

10,11

301,7

Pectinophora gossypiella

9,14

254,0

* Calculados com os dados observados por PATANA et alii (1978). 
A não significância do teste $x^{2}$ entre os ciclos observados e os estimados pelo recíproca da equação da velocidade de desenvolvimento, e o $R^{2}$ próximo de 100\% (Tabela 24) de monstraram uma boa eficiêncja do método da hipérbole no cálcu10 da $\mathrm{T}_{\mathrm{b}}$ e K para B. ovata desenvolvida em $S$. frugiperda.

Entretanto, as estimativas desses parâmetros pe 10 mesmo método usando-se os dados obtidos por PATANA et alii (1978) (Tabela 22) para comparar com os dados observados neste trabalho, foram bem diferentes quanto aos valores de $\mathrm{T}_{\mathrm{b}}$ e $\mathrm{K} \underline{\mathrm{pa}}$ ra B. ovata (Tabela 23), apesar de serem encontrados valores de $R^{2}$ acima de $90 \%$ para todas as equações (Tabela 24). Essas diferenças talvez sejam devidas a aclimatação da B. ovata em regiões diferentes ou ao fator hospedeiro ou então, ao menor. número de temperaturas estudadas por PATANA et alii (1978). Es ses autores só conseguiram obter dados suficientes em 4 temperaturas, o minimo exigido pelo método da hipérbole de acordo com HADDAD e PARRA (1984), pois à $15^{\circ} \mathrm{C}$ foram conseguidos dados insuficientes para se calcular o cilo médio nesta temperatura. 
Tabela 24 - Coeficiente de correlação $\left(R^{2}\right)$ e equações da velocidade de desenvolvimento do parasito B. ovata em 7 espécies hospedeiras, obtidas pelo método da hipérbole.

Hospedeiro

Eq. vel. des. $y=a+b x$

$\mathrm{R}^{2}\left(\frac{\circ}{0}\right)$

\begin{tabular}{llll}
\hline S. frugiperda & $y=-0,0713+5,0484 * 10^{-3} \mathrm{x}$ & 99,4077 \\
\hdashline T. ni & $y=-0,0317+3,4526 * 10^{-3} \mathrm{x}$ & 95,1783 \\
Stigemene acrea & $y=-0,0245+3,0741 * 10^{-3} \mathrm{X}$ & 92,8554 \\
H. virescens & $y=-0,0333+3,4213 * 10^{-3} \mathrm{X}$ & 94,1701 \\
H. zea & $y=-0,0335+3,3147 * 10^{-3} \mathrm{X}$ & 97,1025 \\
S. exigua & $y=-0,0305+3,4048 * 10^{-3} \mathrm{X}$ & 95,6555 \\
P. gossypiella & $y=-0,0359+3,9369 * 10^{-3} \mathrm{X}$ & 92,4847
\end{tabular}

* Calculados com os dados observados por PATANA et alii (1978).

\subsection{Determinaç̃̃o do número de geraçóes de B. ovata PARA ALTINÓPOLIS E MOJI-GUACU EM SÃO PAULO, COM BASE NA TEMPERATURA}

0 número de gerações de $B$. ovata, para Altinöpo lis e Moji-Guaçu (Tabelas 25 e 26) foi calculado de acordo com o item 3.7. De acordo com esses dados, abril e maio são us meses mais favoráveis para o desenvolvimento da população do parasito nas duas localidades estudadas, talvez por isso, B. vata tenha sido coletada com maior freqüência em pupas de Eupseudosoma aberrans e $E$. involuta que em pupas de Thyrinteina 
ann@bia, porque as duas primeiras pragas ocorrem no período fa vorāvel ao parasito e a última ocorre nos meses menos favoráveis.

Tabela 25 - Temperatura efetiva, ciclo em dias e número de gerações/mês de B. ovata, calculados com base no limite inferior de desenvolvi mento e na temperatura média mensal de Altinópolis, SP.

\begin{tabular}{lrrrrr}
\hline Meses & Abr. & Mai. & Jun. & Jul. & Ago. \\
\hline Temp. média $\left({ }^{\circ} \mathrm{C}\right)$ & 22,7 & 21,1 & 19,1 & 19,3 & 21,0 \\
Temp. efetiva ( $\left.{ }^{\circ} \mathrm{C}\right)$ & 8,6 & 7,0 & 5,0 & 5,2 & 6,9 \\
Ciclo (dias) & 23,0 & 28,3 & 39,6 & 38,1 & 28,7 \\
№ gerações & 1,3 & 1,1 & 0,8 & 0,8 & 1,0 \\
\hline
\end{tabular}

Tabela 26 - Temperatura efetiva, ciclo e nưnero de gerações/mês de B. ovata, com base no limite inferior de desenvolvimento e na temperạtura média mensal de Moji-Guaçu, SP.

\begin{tabular}{lrrrrr}
\hline Meses & Abr. & Mai. & Jun. & Jul. & Ago. \\
\hline Temp. média $\left({ }^{\circ} \mathrm{C}\right)$ & 20,5 & 18,4 & 16,6 & 16,4 & 18,3 \\
Temp. efetiva $\left({ }^{\circ} \mathrm{C}\right)$ & 6,4 & 4,3 & 2,5 & 2,3 & 4,2 \\
Ciclo (dias) & 30,9 & 46,0 & 79,2 & 86,1 & 47,1 \\
№ gerações & 1,0 & 0,7 & 0,4 & 0,3 & 0,6 \\
\hline
\end{tabular}


Pode-se verificar ainda (Tabelas 25 e 26) que B. ovata desenvolve-se melhor em Altinópolis "que em Moji-Guaçu. Naquela área atinge cerca de 2,5 gerações durante os períodos abril-maio e junho-agosto, enquanto as respectivas pragas E. aberrans e E. involuta dão apenas uma geração (OHASHI, 1978) e T. arnøbia cerca de 1,5 geração (BERTI FILHO, 1974 e MACEDO, 1975). Portanto, se esse parasitóide for usado no controle bio lógico dessas pragas sugere-se a área de Altinópolis, porque B. ovata tem dificuldade de se desenvolver em Moji-Guaçu a par tir do mês de maio.

Apesar da temperatura ser considerada como um dos principais fatores ecológicos (SILVEIRA NETO et alii, 1976) e um dos elementos climáticos que afetam mais diretamente os insetos (HADDAD e PARRA, 1984) essas previsões não têm caráter definitivo, porque cada inimigo natural é um simples componente ecológico dentro de um complexo ecossistema e portanto a eficiência de um parasito, depende também de outros fatores: umidade, chuva, sincronismo populacional entre inimigo e hospedeiro, alimento para os parasitos adultos, presença de hospedeiros alternativos, competição com outras espécies, hiperpara sitos, uso de defensivos, outras práticas culturais, etc. (MESSENGER et alii, 1976). Pode-se salientar ainda, que esses últí mos fatores dependentes da ação do homem, especialmente o uso de defensivos, devem ser cuidadosamente programados para as áreas e períodos favoráveis ao desenvolvimento de B. ovata. 


\subsection{INTERACÃO PARASITO-HOSPEDEIRO}

\subsubsection{CONSUMO DE $\mathrm{O}_{2}$}

A respiração da pupa hospedeira foi profundamen te alterada pelo parasitismo (Figura 23 e Tabela 27). A análise estatística desses dados pelo teste F (Tabela 28), explicou

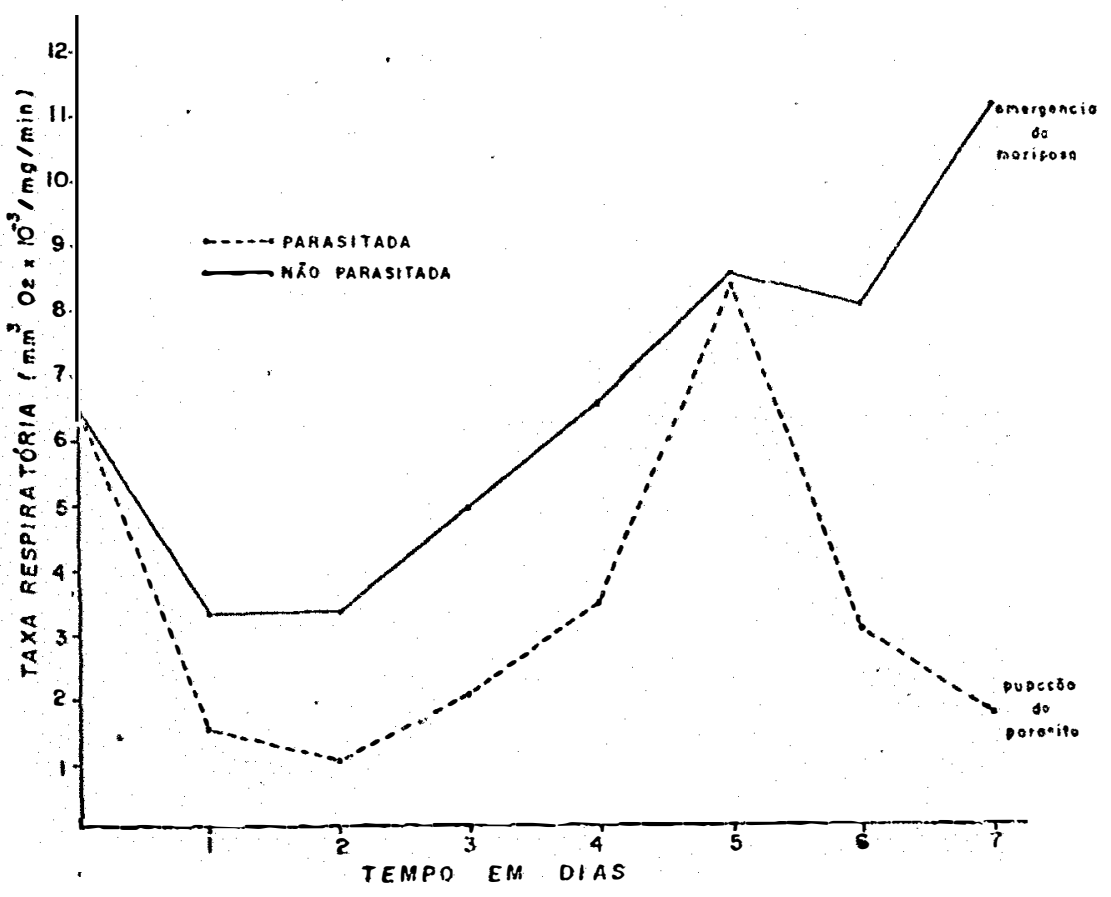

Figura 23 - Respiração de pupas de $S$. frugiperda parasitadas e não parasitadas por $B$. ovata. 
Tabela 27 - Taxa respiratória em $\mathrm{rm}^{3} \mathrm{O}_{2} \times 10^{-3} / \mathrm{mg} / \mathrm{min}$ de pupas de $S$. frugiperda parasitadas e não parasitadas por B. ovata.

\begin{tabular}{cccccc}
\hline \multirow{2}{*}{$\begin{array}{c}\text { Dias após } \\
\text { parasitismo }\end{array}$} & \multicolumn{2}{c}{ Pupas parasitadas } & & \multicolumn{2}{c}{ Pupas não parasitadas } \\
\cline { 2 - 3 } \cline { 5 - 6 } & Média & I.V. & & Média & I.V. \\
\hline 0 & 6,457 & $4,251-8,185$ & & 6,540 & $4,961-7,378$ \\
1 & 1,536 & $0,957-2,657$ & & 3,264 & $2,643-4,024$ \\
2 & 1,042 & $0,362-1,634$ & & 3,315 & $2,808-4,046$ \\
3 & 1,962 & $0,895-3,052$ & & 4,894 & $3,639-5,983$ \\
4 & 3,427 & $1,224-5,653$ & & 6,463 & $5,156-7,906$ \\
5 & 8,292 & $6,322-10,867$ & & 8,500 & $7,013-14,057$ \\
6 & 2,986 & $1,241-4,330$ & & 8,003 & $6,573-10,849$ \\
7 & 1,654 & $0,919-2,593$ & & 11,116 & $8,605-13,422$ \\
\hline
\end{tabular}

Tabela 28 - Anālise de variância da taxa respiratória de pupas de $S$. frugi perda parasitadas e não parasitadas por B. ovata.

\begin{tabular}{lrrrrr}
\hline $\begin{array}{l}\text { Causa da } \\
\text { variação }\end{array}$ & G.L. & S.Q. & Q.M. & F & Níve1 : \\
\hline Dias (DI) & 7 & 29,7802 & 4,2543 & $97,75^{* *}$ & 0,00 \\
Resíduo (a) & 72 & 3,1334 & 0,0435 & & \\
\hline Parcelas & 79 & 32,9136 & & & \\
\hline Parasitismo (PA) & 1 & 19,1710 & 19,1710 & $394,61^{* *}$ & 0,00 \\
Interação DI.x PA & 7 & 12,3442 & 1,7634 & $36,29^{* *}$ & 0,00 \\
Resíduo (b) & 72 & 3,4979 & 0,0485 & & \\
\hline Total & 159 & 67,9269 & & & \\
\hline
\end{tabular}

Dados transformados para $\sqrt{x+0,8}$ 
que houve grande significância na taxa respiratória para dias, parasitismo (pupas parasitadas e não parasitadas) e interação dias x parasitismo. Nessa interação (Tabela 29), os ünicos dias que a taxa respiratória não diferiu estatisticamente ao nível de 1\% de probabilidade foi, no dia zero, logo após ao parasitismo, e no dia 5 , quando as pupas parasitadas já estavam in.. discutivelmente mortas pela larva do parasito no 59 instar. E certamente neste dia, o parasito foi o maior responsável pela alta taxa respiratória, porque provavelmente desenvolveu uma maior atividade metabólica para transformar o alimento consumi do em produtos de reserva para as fases seguintes. Foi realmen te no 59 instar que o parasito apresentou o maior crescimento relativo (Tabela 2), quando praticamente todas suas dimensões foram dobradas em relação ao instar anterior, necessitando por tanto, metabolizar e respirar mais que nos outros estägios. O desenvolvimento do parasito foi observado de acordo com o item 3. 8.1 .

0 teste Tukey à $5 \%$ de probabilidade das médias da taxa respiratória para dias dentro de pupas não parasitadas (Tabela 30), mostrou que a respiração no dia zero foi maior que nos dias 1 e 2 . Havendo portanto, um decréscimo inicial na respiração dessas pupas, que é considerado normal na pupação dos insetos por THOMPSON (1980). Após esse período, a respiração aumentou gradativamente atê a emergência das mariposas de S. frugiperda. O teste de Tukey aplicado às médias diārias da taxa respiratória das pupas parasitadas (Tabela 31), também de 
Tabela 29 - Desdobramento dos graus de Iiberdade da interação parasitismo* $x \operatorname{dias}(D I)$.

\begin{tabular}{lrrrrr}
\hline Causa da variação & G.L. & S.Q. & Q.M. & F & Níve1\% \\
\hline Parasitismo den. dia 0 & 1 & 0,0016 & 0,0016 & $0,03 \mathrm{~ns}$ & 85,42 \\
Parasitismo den. dia 1 & 1 & 1,2785 & 1,2785 & $26,31^{* *}$ & 0,00 \\
Parasitismo den. dia 2 & 1 & 2,2923 & 2,2923 & $47,18^{* *}$ & 0,00 \\
Parasitismo den. dia 3 & 1 & 2,6832 & 2,6832 & $55,23^{* *}$ & 0,00 \\
Parasitismo den. dia 4 & 1 & 2,1666 & 1,1666 & $44,59^{* *}$ & 0,00 \\
Parasitismo den. dia 5 & 1 & 0,0044 & 0,0044 & $0,09 \mathrm{~ns}$ & 76,18 \\
Parasitismo den. dia 6 & 1 & 5,3196 & 5,3196 & $109,49^{* *}$ & 0,00 \\
Parasitismo den. dia 7 & 1 & 17,7688 & 17,7688 & $365,74^{* *}$ & 0,00 \\
\hline
\end{tabular}

* pupas parasitadas e não parasitadas.

Tabela 30 - Teste de Tukey a $5 \%$ de probabilidade para dias dentro de pupas de S. frugiperda não parasitadas.

\begin{tabular}{ccc}
\hline Dia & \multicolumn{2}{c}{ Média } \\
\hline 7 & 3,4447 & $\mathrm{a}$ \\
5 & 3,0359 & $\mathrm{~b}$ \\
6 & 2,9581 & $\mathrm{bc}$ \\
0 & 2,7047 & $\mathrm{c}$ \\
4 & 2,6903 & $\mathrm{c}$ \\
3 & 2,3808 & $\mathrm{~d}$ \\
2 & 2,0258 & $\mathrm{e}$ \\
1 & 2,0127 & $\mathrm{e}$ \\
\hline
\end{tabular}

DMS $=0,2957$ 
Tabela 31 - Teste de Tukey a $5^{\circ}$ de probabilidade para dias dentro de pupas de $S$. frugiperda parasitadas por B. ovata.

\begin{tabular}{ccc}
\hline Dia & Média \\
\hline 5 & 3,0060 a \\
0 & 2,6865 & b \\
4 & 2,0320 & $\mathrm{c}$ \\
6 & 1,9266 & $\mathrm{~cd}$ \\
3 & 1,6482 & de \\
7 & 1,5595 & ef \\
1 & 1,5070 & ef \\
2 & 1,3487 & $\mathrm{f}$ \\
\hline
\end{tabular}

monstrou um decréscimo inicial (dias 1 e 2 ), e que diferiu estatisticamente do decréscimo das não parasitadas. Evidenciando assim, que só a postura e/ou ovo, alterou a respiração no dia 1 , porque a larva eclodiu entre os dias 1 e 2 . Após esse perío do, a respiração na pupa parasitada aumentou lentamente até o dia 4 (Figura 23 e Tabe1a 31), que corresponde, provavelmente ao desenvolvimento dos 4 primeiros instares da larva parasita. No dia 5 ocorreu um aumento brusco na respiração, explicado an teriormente para em seguida decrescer (dia $5>$ dia $6>$ dia 7 ) ra pidamente, devido o início da pupação do parasito.

Resultados semelhantes a esses foram obtidospor THOMPSON (1980), apesar de estudar a respiração de pupas de Trichoplusia ni parasitadas por Brachymeria intermedia. 


\subsubsection{REDUÇÃO DO PESO DO HOSPEDEIRO}

Tanto as pupas parasitadas como as não parasita das, perderam peso durante o período estudado (Figura 24 e Tabela 32). A análise desses dados de acordo com o item 3.8.2., demonstrou pelo teste $F$ (Tabela 33) uma redução do peso muito significativa para dias, para parasitismo e para a interação dias $x$ parasitismo. O desdobramento dessa interação (Tabela 34), demonstrou que, exceto no dia 1 (24 horas do parasitismo), em todos os demais dias, a redução do peso diferiu estatisticamen te entre as pupas parasitadas e não parasjtadas.

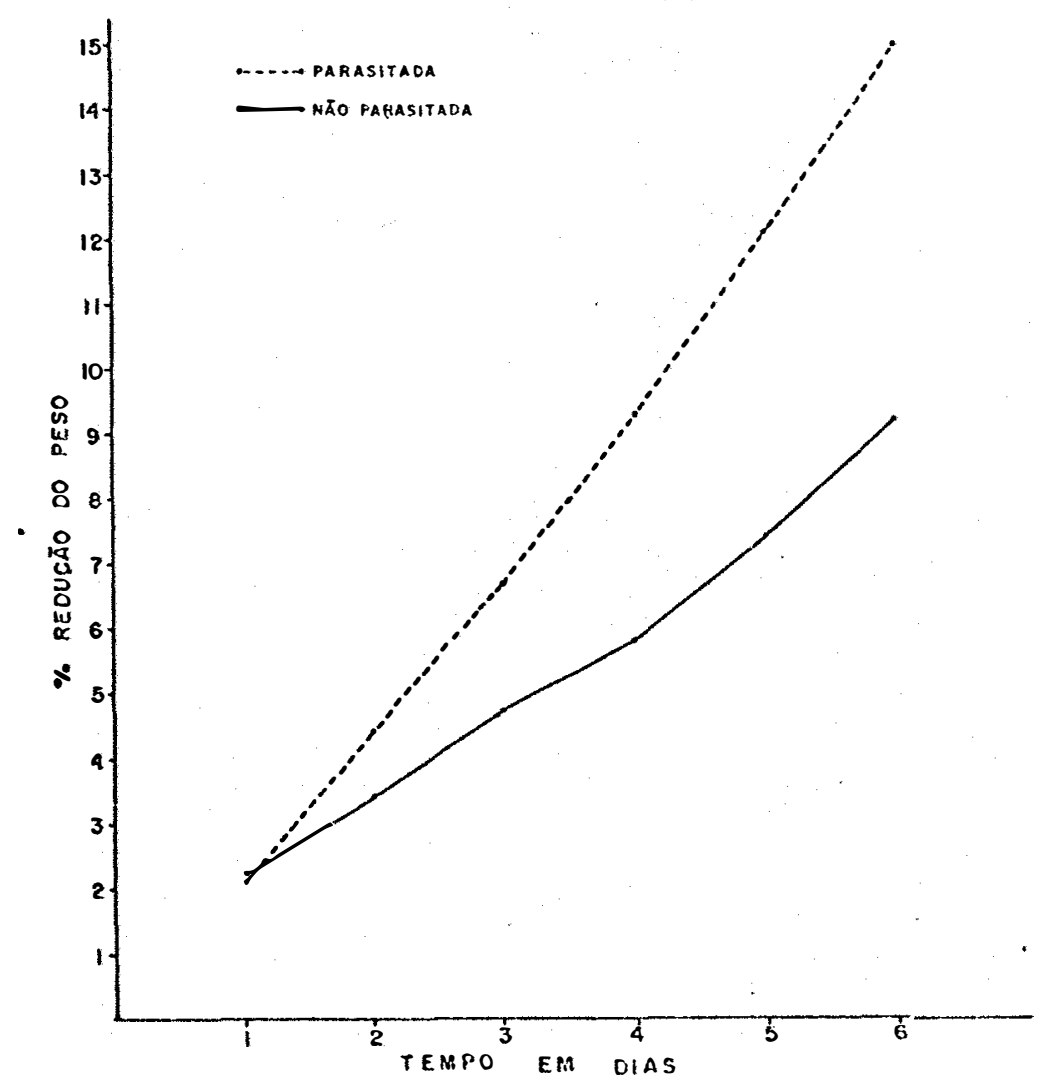

Figura 24 - Percentagem de redução do peso de pupas de $S$. frugiperda parasitadas e não parasitadas por B. ovata. 
Tabela 32 - Percentagem de redução (acumulativa) do peso de pupas de $S$. frugiperda parasitadas e não parasitadas por B. ovata à temperatura de $30^{\circ} \mathrm{C}$.

\begin{tabular}{cccccc}
\hline \multirow{2}{*}{$\begin{array}{c}\text { Dias após } \\
\text { parasitismo }\end{array}$} & \multicolumn{2}{c}{ Pupas parasitadas } & & \multicolumn{2}{c}{ Pupas não parasitadas } \\
\cline { 2 - 3 } \cline { 6 - 6 } & Média & I.V. & & Média & I.V. \\
\hline 1 & 2,08 & $1,50-3,93$ & & 2,15 & $1,70-2,60$ \\
3 & 4,38 & $3,51-6,35$ & & 3,41 & $2,42-3,94$ \\
4 & 6,66 & $5,30-9,66$ & & 4,67 & $3,95-5,26$ \\
5 & 9,30 & $7,42-13,34$ & & 5,80 & $4,97-6,54$ \\
6 & 12,15 & $9,89-17,14$ & & 7,43 & $6,38-8,35$ \\
& 15,00 & $11,66-21,32$ & & 9,19 & $8,00-10,74$ \\
\hline
\end{tabular}

Tabela 33 - Anālise da variância da percentagem de redução (acumulativa) do peso de pupas de $S$. frugiperda parasitadas e ñão parasitadas por B. ovata.

\begin{tabular}{lrrrrr}
\hline Causa da variação & G.L. & S.Q. & Q.M. & F & Nivel\% \\
\hline Dia (DI) & 5 & $\begin{array}{r}3869,1430 \\
117,0516\end{array}$ & $\begin{array}{r}773,8286 \\
1,0267\end{array}$ & $753,65^{* *}$ & 0,00 \\
Resíduo (a) & 114 & & & \\
\hline Parcelas & 119 & 3986,1940 & & & \\
\hline Paras (PA) & 1 & 489,1860 & 489,1859 & $389,37^{* *}$ & 0,00 \\
Interação DI x PA & 5 & $\begin{array}{r}204,3402 \\
143,2211\end{array}$ & $\begin{array}{r}40,8680 \\
1,2563\end{array}$ & $32,52^{* *}$ & 0,00 \\
Resĩduo (b) & 114 & & & \\
\hline Total & 239 & 4822,9413 & & & \\
\hline
\end{tabular}

Dados transformados para arc sen $\sqrt{x / 100}$

$\mathrm{PA}=$ parasitismo (pupas parasitadas e não parasitadas) 
Tabela 34 - Desdobramento dos graus de liberdade de interação parasitismo* $x$ dias.

\begin{tabular}{lrrrrrr}
\hline Causa da variacão & G.L. & S.Q. & Q.M. & F & Níve1\% \\
\hline Paras* den. dia 1 & 1 & 0,4002 & 0,4002 & $0,31 \mathrm{~ns}$ & 57,35 \\
Paras den. dia 2 & 1 & 20,2660 & 20,2660 & $16,13^{* *}$ & 0,01 \\
Paras den. dia 3 & 1 & 59,9696 & 59,9696 & $47,73^{* *}$ & 0,00 \\
Paras den. dia 4 & 1 & 143,6077 & 143,6077 & $114,30^{\star *}$ & 0,00 \\
Paras den. dia 5 & 1 & 206,3098 & 206,3098 & $164,21^{* *}$ & 0,00 \\
Paras den. dia 6 & 1 & 262,9728 & 262,9728 & $209,31^{* *}$ & 0,00
\end{tabular}

* pupas parasitadas e não parasitadas

Tabela 35 - Teste de Tukey a 5\% de probabilidade para dias dentro de pupas de $S$. frugiperda não parasitadas.

\begin{tabular}{crcc}
\hline Dia & \multicolumn{3}{c}{ Média } \\
\hline 6 & 17,6885 & $\mathrm{a}$ & \\
5 & 15,8117 & $\mathrm{~b}$ & \\
4 & 13,9320 & $\mathrm{c}$ & \\
3 & 12,4668 & $\mathrm{~d}$ \\
2 & 10,6154 & $\mathrm{e}$ \\
1 & $8,4065 \quad$ & $\mathrm{f}$ \\
\hline
\end{tabular}

DMS $=0,9775$ 
Tabela 36 - Teste de Tukey a $5 \%$ de probabilidade para dias dentro de pupas de $S$. frugiperda parasitadas por B. ovata.

\begin{tabular}{|c|c|c|}
\hline Dia & Média & \\
\hline 6 & 22,8165 & $\mathrm{a}$ \\
\hline 5 & 20,3539 & $\mathrm{~b}$ \\
\hline 4 & 17,7216 & $c$ \\
\hline 3 & 14,9157 & $d$ \\
\hline 2 & 12,0390 & $\mathrm{e}$ \\
\hline 1 & 8,2065 & $\mathrm{f}$ \\
\hline
\end{tabular}

IMS $=0,9775$

0 teste de Tukey a $5 \%$ de probabilidade para as médias diārias da redução de peso dentro de pupas não parasita das (Tabela 35) e dentro de pupas parasitadas (Tabela 36), evi denciou que em cada caso, as médias diferem estatisticamente entre si.

A maior perda de peso das pupas parasitadas, pro vavelmente se deve a dois fatores:

a) principalmente pela perda d'água atravēs das vịas respirató rias, porque esses hospedeiros tornam-se incapazes de acionar os mecanismos reguladores da transpiração respiratória, mas que devem funcionar normalmente nas pupas não parasitadas. De acordo com BATISTA (1974), a maior perda d'água nos insetos que vivem expostos às condições atmosféricas nor- 
mais, ocorre por transpiração via traqueal, a qual pode ser regulada através de alguns mecanismos, como: aumento da res piração cutânea e redução do número de espirâculos abertos.

b) parte do alimento ingerido pelo parasito transforma-se em e nergia utilizada nos processos metabólicos desse inseto.

Assim supõe-se que esses dois fatores começam a atuar nas pupas parasitadas a partir do dia 2, porque dai em diante existe diferença estatistica entre os dois tratamentos (Tabela 34) e com a eclosão da larva, ela passa atuar mais danosamente ao hospedeiro.

\subsubsection{DESENVOLVIMENTO DE B. ovata EM HOSPEDEIRO MORTO EM NITROGÊHIO LIQUIDO $\left(\mathrm{N}_{2}\right)$}

- De 35 pupas de $S$. frugiperda mortas e parasitadas, emergiram 15 fêmeas e 6 machos de $B$. ovata, aparentemente normais e cujo ciclo foi igual aqueles desenvolvidos em pupas normais à temperatura de $30^{\circ} \mathrm{C}$. De 15 pupas mortas e não pa rasitadas, não emergiu nenhuma mariposa.

Esses resultados demonstram que B. ovata é um pa rasitóide saprófita facultativo e portanto independe da vida do hospedeiro para qualquer interação fisiológica. 


\subsubsection{AVALIACẼO DA INTERACÃO PARASITO-HOSPEDEIRO}

Como foi relatado nos itens 4.7.1. e 4.7.2., B. ovata provavelmente matou o hospedeiro a partir do 20 dia de parasitismo, porque foi quando ocorreu a menor taxa respịratória e iniciou a diferença na redução do peso entre as pupas pa rasitadas e não parasitadás. Além disso foi observado no 2 ? dia que as pupas parasitadas apresentavam-se imóveis e a par tir do 39 dia um cheiro pütrido e uma deterioração dos tecidos desses insetos, enquanto as pupas não parasitadas, não apresen taram essas características.

Portanto é provável que B. ovata no início de seu desenvolvimento mate seu hospedeiro, porque independe de um metabolismo fisiológico regulado pelo hospedeiro para assegurar seu completo desenvolvimento, como acontece com B. inter media (THOMPSON, 1980). Assim sugere-se a possibilidade do desenvolvimento de uma dieta artificial para B. ovata, porque e $\underline{s}$ se inseto conseguiu desenvolver-se sobre matéria morta. 


\section{CONCLUSÕES}

Com base nas observações e resultados obtidos com Brachymeria (B.) ovata (Say, 1824) no presente trabalho, po dem ser estabelecidas as seguintes conclusões:

1. A temperatura afeta nitidamente a velocidade de desenvolvimento.

2. A faixa ótima estimada para o desenvolvimento é de $25^{\circ} \mathrm{C}$ à $30^{\circ} \mathrm{C}$.

3. A constante térmica para o ciclo (ovo-emergência do adulto) de B. ovata é de 198 graus-dia, tomando-se por base o limiar térmico estimado de $14,13 G D$.

4. A pupa de spodoptera frugiperda é um bom hospedeiro alterra tivo para reproduzir B. ovata em condições de laboratōrio, pela alta porcentagem de emergência de adultos desse parasi 
tóide numa proporção de 2 fêmeas: 1 macho.

5. B. ovata é um parasito saprófita facultativo que mata seu hospedeiro no início do parasitismo.

6. O crescimento do diâmetro do espiräculo è o método mais exa to para distinguir os instares larvais de B. ovata.

7. 0 crescimento da cápsula cefálica de B. ovata obedece a regra de Dyar.

8. Com base na temperatura, a ärea de Altinópolis (SP) è mais favorável ao desenvolvinento de B. ovata do que a ārea dé Moji-Guaçu (SP) .

9. Os espécimens brasileiros de B. ovata são morfologicamente diferentes dos exemplares neárticos, principalmente quanto às manchas amarelas e pretas das pernas desses insetos. 


\section{LITERATURA CITADA}

ASKEW, R.R., 1971. Parasitic insects. New York, American Elsevier Publishing Company, Inc., 316p.

ATKINS Jr., E.L., 1958. The western tussock moth, Hemerocampa vetusta (Bdv.), on Citrus in southern California. Journal. of Economic Entomology. Menasha, 51(6): 762-765.

BATISTA, G.C. de, 1974. Fisiologia dos Insetos. Piracicaba, ESALQ/USP, Depto de Entomologia, 304p. [mimeografado].

BERTI FILHO, E., 1974. Biologia de Thyrinteina arnobia (Stoll, 1782) (Lepidoptera, Geometridae) e observações sobre a ocorrência de inimigos naturais. Piracicaba, ESALQ/USP, 74p. [Tese de Doutoramento]. 
BERTI FILHO, E., 1979. Controle biológico dos insetos. Piracicaba, ESALQ/USP, Depto de Entomologia, 96p. [mimeografado] .

BERTI FILHO, E., 1981. Insetos associados a plantações de espécies do gênero Eucalyptus nos Estados da Bahia, Espírito Santo, Mato Grosso do Sul, Minas Gerais e São Paulo. Piracicaba, ESALQ/USP, 176p. [Tese de Docência Livre].

BORTOLI, S.A. de; J.R.P. PARRA e F.M. LARA, 1982. Parasitismo em Hedylepta indicata (Fabricius, 1775) (Lepidoptera-Pyralidae), na região de Jaboticabal, SP. Anais da Sociedade Entomológica do Brasil. Jaboticabal, 11(1): 167-168.

BURKS, B.D., 1936. The Illinois species of Brachymeria (Hymenoptera, Chalcididae). Transactions of the Illinois State. Academy of Science. Urbana, 29: 251-254.

BURKS, B.D., 1960. A revision of the genus Brachymeria Westwood in America North of Mexico (Hymenoptera: Chalcididae). Transactions of the American Entomological Society. Philadelphia, 86: 225-273.

COSTA LIMA, A.M., 1962. Himenópteros. In: COSTA LIMA, A.M. Insetos do Brasil. Rio de Janeiro, ENA, V.12, pt.2. [Série didática, no 14]. 
DE SANTIS, L., 1969. Chalcidoideos brasileños parasitos de "Euselasia" (Hymenoptera Y Lepidoptera). Boletin do Museu. de História Natural da Universidade Federal de Minas Gerais. Belo Horizonte, 4: 1-6.

DE SANTIS,L., 1980. Catalogo de los himenopteros brasileños de la série parasitica incluendo bethyloidea. Curitiba, Editora da Universidade Federal do Paraná, 395p.

DOUTT, R.L., 1959. The biology of parasitic hymenoptera. Annual Review of Entomology. Palo Alto, 4: 161-182.

DOWDEN, P.B., 1935. Brachymeria intermedia (Nees) a primary parasite, and B. compsilurae (Cwfd.) a secondary parasite, of the gypsy moth. Journal of Agricultural Research. Washington, $50(6): 495-523$.

DROOZ, A.T. e D.M. BENJAMIN, 1956. Parasites fron two jack-pine budworm outbreaks on the upper penninsula of Michigan. Journal of Economic Entomology. Menasha, 49 (3): 412-413.

GALLO, D.; O. NAKANO; S. SILVEIRA NETO; R.P.L. CARVALHO; G.C. de BATISTA; E. BERTI FILHO; J.R.P. PARRA; R.A. ZUCCHI e S.B. ALVES, 1978. Manual de Entomologia Agrícola. São Paulo, Editora Agronômica Ceres. $531 \mathrm{p}$. 
GENUNG, W.G., 1959. Notes on the syntomid moth Lymire edwardsi (Grote) and its control as a pest of Ficus in south Florida. Florida Entomologist. Gainesville, 42(1): 39-42.

HADDAD, M.L. e J.R.P. PARRA, 1984. Métodos para estimar os 1imites térmicos e a faixa ótima de desenvolvimento das diferentes fases do ciclo evolutivo de insetos. Piracicaba, Fundação de Estudos Agrários Luiz de Queiroz, 12p.

LANDIN, C.C. e D. BEIG, 1966. Manuial de laboratório para: Citologia, Histologia e Embriologia. Rio Claro, Faculdade de Filosofia, Ciências e Letras de Rio Claro, 22p. [mimeografado].

LEONARD, S.H. e J.M. RINGO, 1978. Analysis of male courtship patterns and mating behavior of Brachymeria intermedia. Annals of the Entomological Society of America. Columbus, 71: $817-826$.

LOURENCAO, A.L.; E. BERTI FILHO e M.C.V.D. FERRAZ, 1982. Inimigos naturais de Mocis latipes (Guenée, 1852). Bragantia. Campinas, $\underline{41}(9): 237-240$.

MACEDO, N., 1975. Estudo das principais pragas das ordens Lepidoptera e Coleoptera dos eucaliptais do Estado de São Paulo. Piracicaba, ESALQ/USP, 87p. [Dissertação de Mestrado]. 
MESSENGER, P.S.; E. BILIOTTI e R. van den BOSCH, 1976. The importance of natural enemies in integrated control. In: HUFFAKER, C.B. e P.S. MESSENGER, Coord. Theory and practice of biological control. New York, Academic Press, p.543-563.

OGUNWOLU, E.O. e D.H. HABECK, 1975. Comparatives Iife-histories of three Mocis spp, in Florida (Lep.:Noctuidae). Florida Entomologist. Gainesville, 58(2): 97-103.

OHASHI, 0.S., 1978. Biologia e caracteres morfológicos diferenciais de Eupseudosoma aberrans Schaus, 1905 e Eupseudosoma involuta (Sepp, 1852) (Lepidoptera, Arctiidae) e ocorrência de inimigos naturais. Piracicaba, ESALQ/USP, 99p. [Dissertação de Mestrado].

PARKER, H.L., 1924. Recherches sur les formes post-embryonnaires des chalcidiens. Annales de la Société Entomologique de France. Paris, 93: 261-379. 
PARRA, J.R.P., 1979. Biologia dos Insetos. Piracicaba, ESALQ/ USP, Deptọ de Entomologia, 383p. [mimeografado].

PARRA, J.R.P., 1981. Biologia comparada de Perileucoptera cofbeella (Guérin-Mèneville, 1842) (Lepidoptera-Lyonetiidae), visando seu zoneamento ecológico no Estado de São Paulo. Piracicaba, ESALQ/USP, 96p. [Tese de Docência Livre].

PARRA, J.R.P. e M.L. HADDAD, 1983. Determinação do número de instares de inșetos. Piracicaba, ESALQ/USP, Deptọ de Entomologia, 30p. [mimeografado].

PATANA, R., 1979. Progeny production and longevity of individual pairs of Brachymeria ovata on Heliothis virescens in laboratory. Environmental Entomology. Maryland, $\underline{8}(6):$ 987-988.

PATANA, R.; C.G. JACKSON e R.E, FYE, 1978. Development of Brachymeria ovata in six lepidopteran hosts. The Soutwestern Entomologist. (s.l.), $\underline{3}(4): 266-270$.

ROJAS-ROUSSE, D. e M. BENOIT, 1977. Morphology and biometry of larval instars of Pimpla instigator (F.) (Hymenoptera: Ichneumonidae). Bulletin of Entomological Research. London, 67: $129-141$. 
SAVESCU, A., 1965. Constantele dezvoltarii insectelor polivoltine si importanta lor pentru teoria si practica protectiei plantelor. Anelele Institutul Central de Cercetari Agricole. Sectiei de Protectia Plantelor. Bucaresti, $\underline{3}$ : 289-304.

SILVA, A.G.D.A.; C.R. GONCALVES; D.M. GALVAO; A.J.L. GONÇALVES; J. GOMES; M.N. SILVA e L. SIMONI, 1968. Quarto Catảlogo dos Insetos que vivem nas plantas do Brasil seus parasitos e predadores. Rio de Janeiro, Deptọ de Defesa e Inspeção Agropecuäria, V.1, pt.2.

SILVEIRA NETO, S.; O. NAKANO; D. BARBIN e N.A.V. NOVA, 1976. Manual de Ecologia dos Insetos. São Paulo, Editora Agronômica Ceres, $419 \mathrm{p}$.

SIMSER, D.H. e H.C. COPPEL, 1980. . Courtship and mating behavior of Brachymeria lasus (Hym.:Chalcididae), an imported gypsy moth parasitoid. Entomophaga. Paris, 24(4): 349-355.

THOMPSON, S.N., 1980. Artificial culture techniques for rearing larvae of the chalcidoid parasite, Brachymeria intermedia. Entomologia Experimentalis et Applicata. Amsterdam, 27(2): $133-143$. 
THOMPSON, S.N., 1981. Essential amino-acid requirements of four species of parasitic hymenoptera. Comp. Biochem. Physio1. Great Britain, 69A: 173-174.

UMBREIT, W.W.; R.H. BURRIS e J.F. STAUFFER, 1964. Manometric techniques. Minneapolis, Burgess Publishing Company, 305p.

VANCE, A.M. e H.D. SMITH, 1933. The larval head of parasitic hymenoptera and nomenclature of its parts. Annals of the Entomological Society of America. Columbus, 26: 86-94.

VANZOLINI, P.E. e N. PAPAVERO, Coord., 1967. Manual de coleta e preparação de animais terrestres e de ägua doce. São Pau10, Secretaria da Agricultura do Estado, Depto de Zoologia, $223 p$.

VIGGIANI, G., 1971. Ricerche sugli Hymenoptera Chalcidoidea XXVIII. Studio morfologico comparativo dell'armadura genitale esterna maschile dei Trichogrammatidae. Bolletino del Laboratorio di Entomologie Agraria "Filipo Silvestri" di Portici. Napoli, 29: 181-222.

WEAST, R.C., 1976-1977. Handbook of Chemistry and Physics. Cleveland, CRC Press, p.B-137. 